\title{
Prediction of traffic fatalities and prospects for mobility becoming sustainable-safe
}

\author{
MATTHIJS J KOORNSTRA \\ Insight Consult, Langeweg 70, NL-2371-EJ, Roelofarendsveen, The Netherlands \\ e-mail: matthijs.koornstra@insightconsult.nl
}

\begin{abstract}
The macroscopic trend of road traffic fatalities in any motorized country is described and predicted by the product of rather well fitting functions of time for the exponential decay of fatality risk per unit of traffic volume and the S-shaped Gompertz function of traffic volume growth. This product defines a single-peaked development of road traffic deaths, where its peak reaches earlier the sooner and faster a nation or region motorizes massively. Since in developing countries long series of traffic volume data are absent, another model for the fit and prediction of road traffic fatalities for developing countries is used, based on the relationships of income level per capita with road traffic mortality. Also this model implies that at some point in time road traffic deaths will start declining for ever, also worldwide. After empirically derived corrections for missing or incomplete data and police under-reporting, it is estimated that 1.2 million deaths and almost 8 million serious injuries are caused by road traffic worldwide in 2000. Using realistic income level predictions the new income-dependent model predicts markedly later and higher fatality peaks than the verified time-dependent model. It might be assumed that the developing countries could learn faster to increase their road safety by knowledge transfer from developed countries. Four prediction scenarios are specified for modified income-dependent models of road traffic death and serious injury developments up to 2050. Depending on the scenario the world total of road fatalities begins to reduce soon or only after 2035 with a global peak of about 1.8 million road traffic deaths, where the national fatality reduction starts later the lower the national income per capita is. Without the potentially achievable learning scenario the road fatality reductions in developed countries may not be enough to compensate the road fatality increases in developing countries, while road fatality increases may even occur after 2060 in countries with the lowest levels of income per capita.
\end{abstract}

Keywords. Global road safety; global prediction model; traffic volume; fatality risk; time-dependent model; income-dependent model; prediction scenarios; knowledge transfer.

\section{Introduction}

The non-monotonic development of road traffic deaths and serious injuries in a nation is described by the product of monotonic developments in road traffic volumes (such annual as 
motor vehicle kilometres, measuring exposure to risk) and the fatality and serious injury rates per unit of traffic volume. Research in highly motorized countries has shown that road traffic is growing in a less than exponential way, while the macroscopic trends of casualty rates are shown to decay exponentially (Oppe \& Koornstra 1990). In the early motorization phase of highly motorized nations the traffic growth seems almost exponential and almost linear in the later phases. Motorized traffic growth is restricted by the limited number of future drivers and the limited driving time at their disposal, but the levelling off to a certain traffic growth limit in the future will be slow. The macroscopic growth trend of road traffic, therefore, will be an asymmetric S-shaped function of time, described by the so-called Gompertz function. This function has been shown to fit the growth of motor vehicle kilometres of developed countries rather well, despite periodical deviations and uncertain estimates of growth limits (Koornstra 1997).

It will be noticed that exponential decay of the fatality rate implies an annually constant risk reduction percentage, while a less than exponential traffic growth means an annually decreasing growth percentage. Since the annual traffic growth percentage in the early motorization phase is always larger than the annual risk decay percentage of the exponential fatality rate, the annual numbers of road fatalities are always increasing in the early motorization phase of a nation or region. However, due to the more or less constant annual decay percentage and the ever decreasing annual growth percentage of road traffic volumes, there comes a point in time where after the annual risk decay proportion becomes progressively larger than the annual traffic growth proportion. This implies that road fatalities after that point in time will tend to decrease for ever. Indeed, the product of the asymmetric S-shaped Gompertz function for traffic growth and the exponential decay function of the fatality rate per unit of traffic volume yields by definition an asymmetric single-peaked function for the macroscopic development of road fatalities.

\section{Road traffic injuries and fatalities are decreasing in highly motorized countries}

The USA has the longest available time series of motor vehicle kilometres and road traffic deaths (defined as death within 30 days after the crash), where these data are available from 1923 onward. The figures 1 and 2 show the fit of the above described traffic growth and 'fatality-risk decay models'. The years 1942 to 1945 are omitted for the fit of the motor vehicle

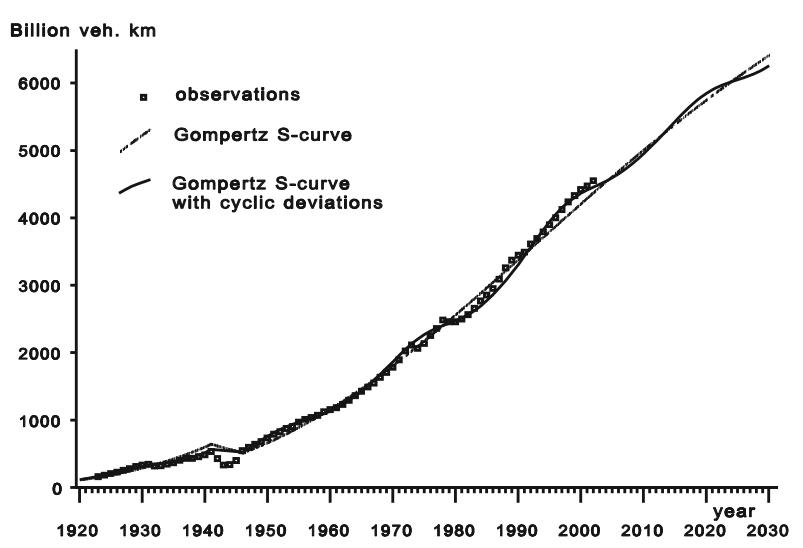

Figure 1. Motor vehicle $\mathrm{km}$. in the USA 1923-2002 and their prediction to 2030 . 


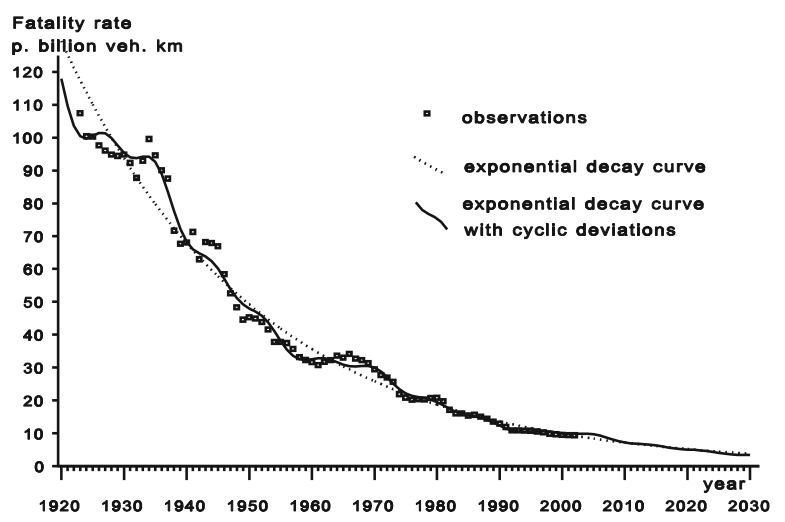

Figure 2. Fatality rates in the USA 1923-2002 and their prediction to 2030.

kilometre growth, while an intervening time lag parameter is added after 1945 in order to model the diminished motor vehicle kilometres in World War II. The periodical deviations around the fitted trend function in both models are fitted by weighted combinations of three harmonic cosine cycles. These cosine cycles with periods of 36, 18, and 9 years for deviations around the exponential risk decay is

$$
R_{t}=\exp \left\{\alpha t+\beta+\sum_{i=1}^{i=3} w_{i} \cos \left[a_{i}\left(t-b_{i}\right)\right]\right\}
$$

for years $t$ with fitted parameter $\alpha, \beta, w_{i}, a_{i}$, and $b_{i}$ improve the fit of the fatality rate decay significantly (why these periods apply is unknown, but they hold for 80 years, while no World War II intervention seems present in the risk decay). Cycles around the S-shaped Gompertz function is

$$
V_{t}=V_{\max } \cdot \exp \left[-\exp \left\{\alpha t+\beta+\sum_{i=1}^{i=3} w_{i} \cos \left[a_{i}\left(t-b_{i}\right)\right]\right\}\right]
$$

for traffic growth in year $t$ in the USA are hardly significant. The product of both fitted curves define the model for the description and prediction of the road fatalities, as shown in figure 3, where we used only the significant deviation cycles in the fatality rate prediction.

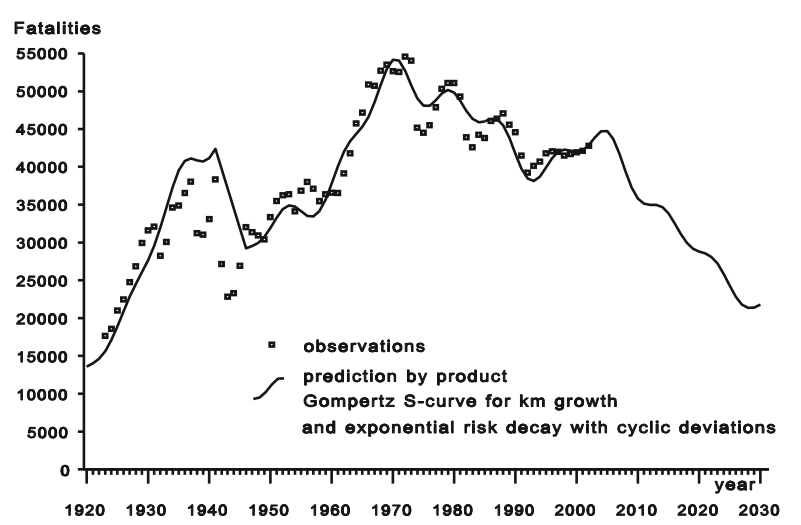

Figure 3. Fitted road fatalities in the USA 1923-2002 and their prediction to 2030. 


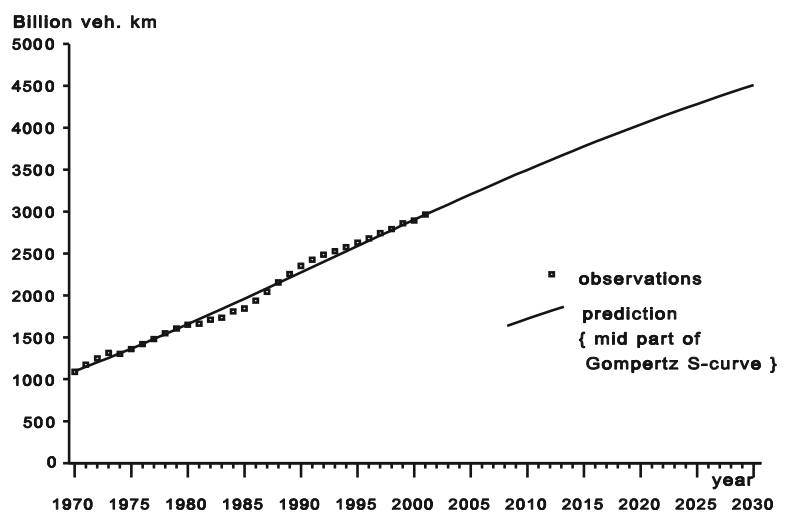

Figure 4. Fitted motor vehicle $\mathrm{km}$ in the EU 1970-2001 and their prediction to 2030 .

Since the fitted traffic growth and cyclically modulated risk decay functions hold for 80 years, the predicted irregular decline from about 42,000 fatalities around 2000 to about 21,500 around 2030 will most likely take place in USA. A declining road deaths trend in USA after the maximum in 1972 of 54,589 fatalities is presently less visible in the European Union (EU) with a maximum of about 81,500 fatalities in 1972. However, the underlying traffic growth and risk decay trends guarantee that the trend in the US fatalities will see a sharper decline in the coming decades than in the past thirty years (by 22\% from 1972 to 2002 and expected to decline by $51 \%$ from 2000 to 2030 ).

For the 15 EU countries the European transport safety council (ETSC, 2003) has assembled the annual motor vehicle kilometres (for some countries derived from motor vehicle and fuel use data) and annual road fatalities from 1970 to 2001 (including GDR before 1990). Before 1970, the annual data of motor vehicle kilometers and sometimes also fatalities were not gathered reliably in southern EU countries. Thus, no comparable data for all EU countries before 1970 are available, whereby the data period is too short to fit cyclic deviations. Therefore, figures 4 to 6 show the fit of the S-shaped traffic growth, exponential risk decay, and resulting single-peaked trend that fits and forecasts the annual fatalities for the $15 \mathrm{EU}$ countries. The predicted traffic growth between 1970 and 2030 is the almost linear mid part of the Gompertz curve.

The resulting prediction of road fatalities in the EU shows a decline from about 40,000 around 2000 to about 12,000 fatalities in 2030 . This is an expected fatality decline of $70 \%$ in

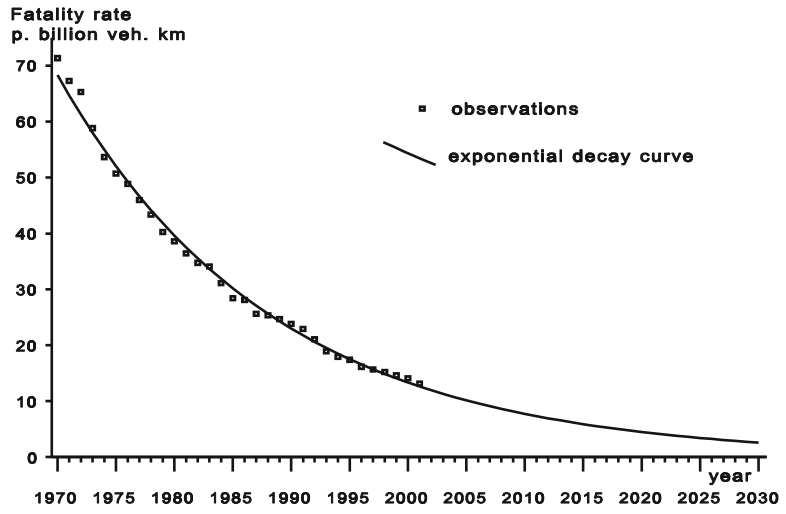

Figure 5. Fitted fatality rates in the EU 1970-2001 and their prediction to 2030. 


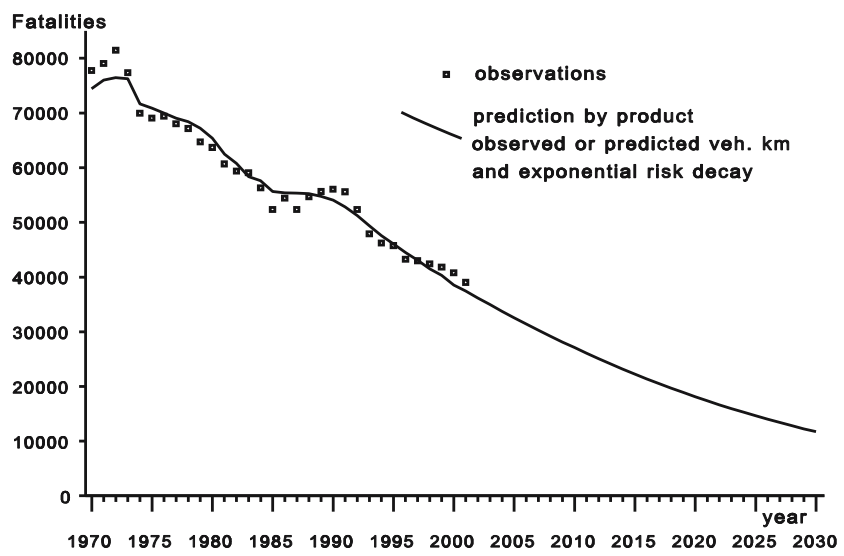

Figure 6. Fitted road fatalities in the EU 1970-2001 and their prediction to 2030 .

three decades. The larger past and expected future reduction of fatalities in the EU than in the USA is mainly due to the larger average annual risk decay of $5.3 \%$ in the EU as compared to the USA with an average annual risk decay of only ' $3.2 \%$ ', while the annual average traffic growth between 1970 and 2000 in the EU and the USA were similar (3.3\% for the EU and $3.1 \%$ for USA). Moreover, the annual traffic growth between 2000 and 2030 is predicted to reduce relatively in a similar way from $1.5 \%$ per year between 2000 and 2010 to $0.8 \%$ per year between 2020 and 2030 in USA and from 2\% per year between 2000 and 2010 to $1.1 \%$ per year between 2020 and 2030 in the EU.

The developments in Canada, Australia, New Zealand, and Japan (Koornstra 1993, 1997) are similar, showing exponential fatality risk decays with annual risk reductions that are closer to the EU than USA. Nearly all high income countries (countries with a gross national per capita greater than US\$ 9,250 in 2000) are now highly motorized. The total reported road fatalities in these high income countries for 2000 is estimated to be about 106,000 and are predicted by the discussed time series model to decrease by $60 \%$ to between 42,000 and 43,000 in 2030 , if the underlying traffic growth and risk decay trends continue.

Semi-motorized countries are upper-middle income countries (GNI/p between US\$ 9,250 and 3,000 in 2000) that generally have no time series of motor vehicle kilometres, but of registered motor vehicles (including motorized two-wheelers) that can be used as a traffic volume measure. However, road fatalities are often inconsistently and/or incompletely gathered over time in upper-middle income countries (for example, Brazil only reports road fatalities for some large city regions). This can even hold for OECD-countries with upper-middle income levels (for example, Mexico only reports fatalities on main rural highways). Moreover, in upper-middle income countries the reported fatalities are generally not defined as road death within 30 days, but as death on the crash spot, while under-reporting of police-reported fatalities is present when compared to hospital surveillance data.

For the total of 10 countries that joined the EU recently (three Baltic states, five CentralEast European countries, Malta, and Cyprus) the ETSC (2003) has assembled the time series of road fatalities and motor vehicle volumes. The fit of the traffic growth and risk decay models and the fit of the resulting fatality trends are shown for the total of the EU-accession countries in figures 7 to 9 .

The model of the exponential fatality risk decay per motor vehicle is modified by an additional time lag parameter for the apparent intervention due to the change from communist to 


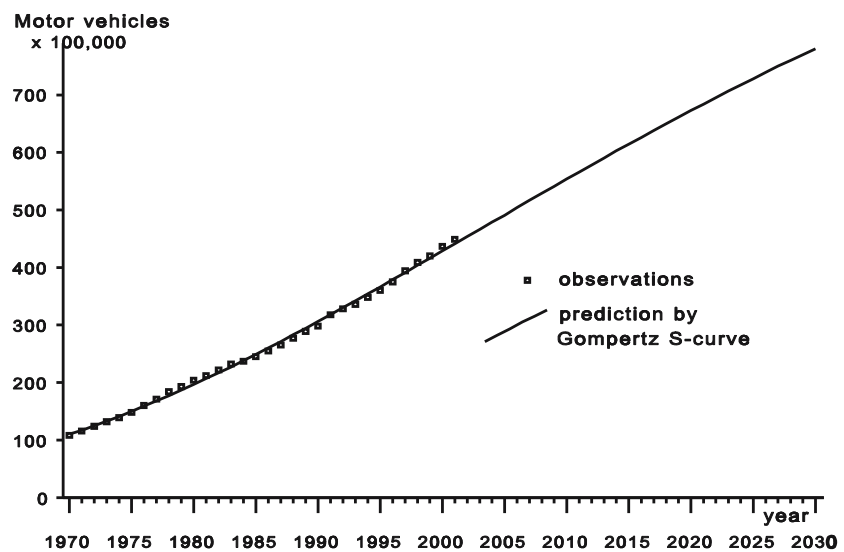

$\begin{array}{lllllllllllll}1970 & 1975 & 1980 & 1985 & 1990 & 1995 & 2000 & 2005 & 2010 & 2015 & 2020 & 2025 & 2030\end{array}$
Figure 7. Fitted motor vehicles in EU-accession countries 19702001 and their forecast.

Fatality rate

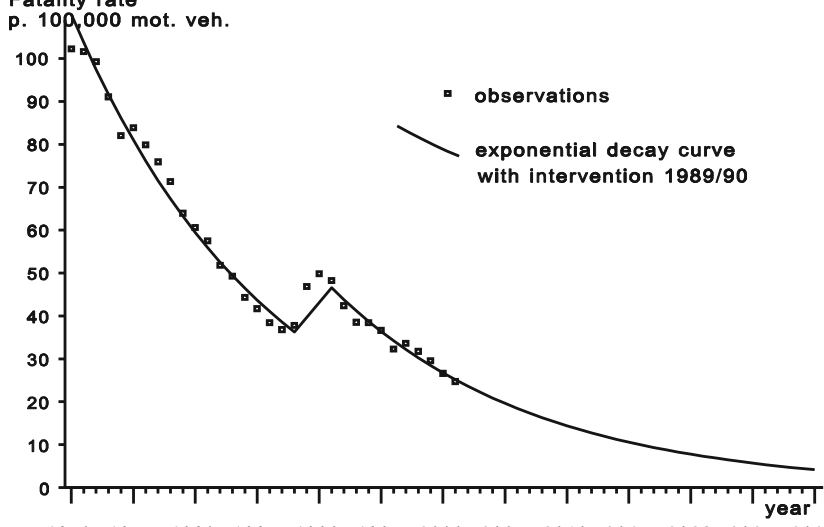

$\begin{array}{lllllllllllll}1970 & 1975 & 1980 & 1985 & 1990 & 1995 & 2000 & 2005 & 2010 & 2015 & 2020 & 2025 & 2030\end{array}$
Figure 8. Fitted fatality rates in EU-accession countries 19702001 and their forecast.

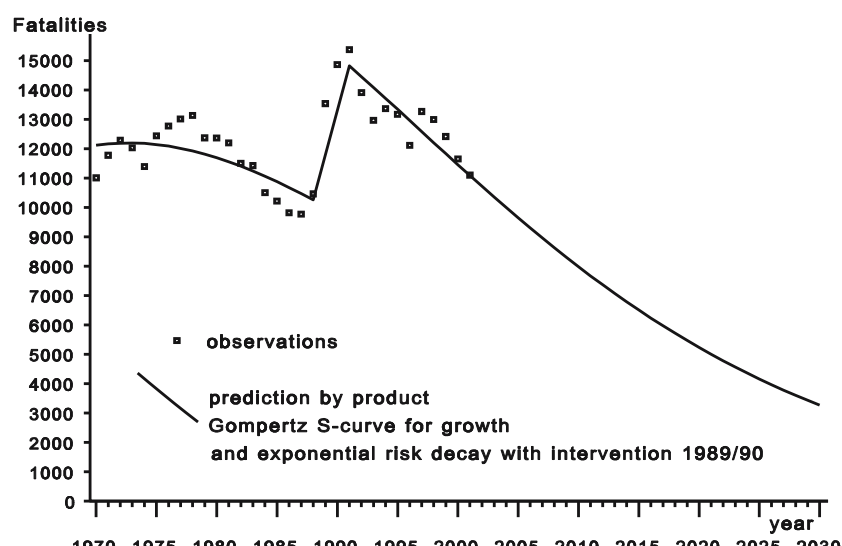

$\begin{array}{lllllllllllll}1970 & 1975 & 1980 & 1985 & 1990 & 1995 & 2000 & 2005 & 2010 & 2015 & 2020 & 2025 & 2030\end{array}$
Figure 9. Fitted road fatalities in EU-accession countries 19702001 and their forecast. 
democratic regimes in 1989/90 (causing higher risk per motor vehicle, due to more kilometres driven per vehicle, higher speeds of more western cars, and less police control).

As figure 9 shows, apart from the decline in the decade before the regime change in 1989/90, the peak of the underlying fatality trend is located around 1992. For these countries the point in time where the annual increase of traffic growth becomes definitely smaller than the annual decay of the fatality rate (about $6 \%$ per year) is about 20 years later than for most high income countries, while the motorization level in these 10 countries ranges now from one motor vehicle per 5 to 3 inhabitants. It shows that the later the motorization evolves, the later the road fatality peak will occur. This also holds for the successively later motorization evolution in Spain, Portugal and Greece with fatality peaks around respectively 1989, 1994, and 1999 where the annual fatality risk decay increased from ' $3.5 \%$ ' before joining the EU to $7 \%$ some years thereafter (ETSC, 2003).

It also will be noticed that earlier the motorization started, the steeper the annual fatality risk decay seems to be, as is exemplified by the annual risk decay in USA with $3.2 \%$, North-West Europe with $5.2 \%$, Central-East European countries with 6\%, and South European countries with $7 \%$. It seems that the later a country motorizes, the higher its annual risk reduction tends to be, which could be explained by the learning and knowledge transfer from the safer motorized countries to the motorizing countries. Most EU-accession countries belong to the upper-middle income countries that are semi-motorized and generally have the potential to apply the best road safety practices of high income countries. Malaysia and Chile, for example, belong to the upper-middle income countries that learned to apply these best road safety practices, as shown by their over $6 \%$ risk decay per unit of motor vehicles and their already decreasing trends in road fatalities (Koornstra, 1993, 1995). However, the road traffic growth in several upper-middle income countries, for example Turkey and South Africa, is still in a relatively early phase of motorization with increasing annual road fatalities. Due to lack of reliable and long enough time series of data on motor vehicles and/or road fatalities in most upper-middle income countries, the above-described model cannot be used for the prediction of most countries with an upper-middle income level. Most upper-middle income countries show a decreasing trend in road fatalities, although several upper middle income countries (especially those with GNI/p levels between US\$4,500 and 3,000) have marked increases in road fatalities.

As discussed, we may expect road fatalities to fall after the motorization level rises above a certain level that shows annual traffic growth proportions that are increasingly lower than the almost constant risk decay proportion, which seems to require that the motorization level is at least higher than one motor vehicle per 6 inhabitants. Using another prediction model that is based on $4 \%$ growth of gross national income per capita (GNI/p) and relationships between GNI/p level, motorization, and road mortality (Koornstra, 2002a), instead of on time-series trends, the road deaths in the upper part of the upper-middle income countries are predicted to reduce and in the lower part to increase in the coming decade.

\section{Road fatalities and serious injuries will rise further in lower-middle income countries and dramatically in low income countries}

The lack of reliable and long enough time series of data on motor vehicles and/or road fatalities and serious injuries applies even more for less motorized countries. Therefore, another model is needed for predictions of road safety developments in less motorized countries. The model applied for the less motorized countries is based on macroscopic relationships of gross 
Table 1. Population, mean GNI/p, and their annual growth\% of countries within eight GNI/p ranges.

\begin{tabular}{|c|c|c|c|c|c|c|}
\hline Group & $\begin{array}{l}\text { Countries within the specified category of } \\
\text { GNI/p-levels }\end{array}$ & $\begin{array}{l}\text { GNI/p } \\
\text { range } \\
1000 \text { US\$ }\end{array}$ & $\begin{array}{l}\text { Pop. } \\
\text { mill. } \\
2000\end{array}$ & $\begin{array}{l}\text { Annual } \\
2000 \\
\text { pop. }\end{array}$ & $\begin{array}{l}\text { growth \% } \\
\text { to } 2015 \\
\text { GNI/p }\end{array}$ & $\begin{array}{l}\text { Mean } \\
\text { GNI/p } \\
1000 \$\end{array}$ \\
\hline 8 & $\begin{array}{l}\text { USA, Japan, North-West and Central-West } \\
\text { European countries, Hong Kong, Singapore, } \\
\text { Brunei }\end{array}$ & $>24 \cdot 0$ & $632 \cdot 5$ & 0.44 & 1.5 & $31 \cdot 33$ \\
\hline 7 & $\begin{array}{l}\text { South European countries, Canada, } \\
\text { Australia, New Zealand, Israel, Arab Emi- } \\
\text { rates }\end{array}$ & $24 \cdot 0-9 \cdot 25$ & $245 \cdot 0$ & $0 \cdot 22$ & 1.8 & $19 \cdot 02$ \\
\hline 6 & $\begin{array}{l}\text { Rep. Korea, Saudi-Arabia, Oman, } \\
\text { Argentina, Uruguay, Chile, Mexico, } \\
\text { Central-East European countries }\end{array}$ & $9 \cdot 25-4 \cdot 50$ & $252 \cdot 5$ & 1.07 & $2 \cdot 1$ & $6 \cdot 27$ \\
\hline 5 & $\begin{array}{l}\text { Poland, Slovakia, Estonia, Libya, Lebanon, } \\
\text { Taiwan, Malaysia, Venezuela, Costa Rica, } \\
\text { Brazil, Panama, Turkey, Gabon, South } \\
\text { Africa, Mauritius }\end{array}$ & $4 \cdot 50-3 \cdot 00$ & $415 \cdot 0$ & $1 \cdot 10$ & $2 \cdot 7$ & 3.55 \\
\hline 4 & $\begin{array}{l}\text { Belarus, Cuba, Jamaica, Dominican Rep. } \\
\text { Colombia, Peru, El Salvador, Guatemala, } \\
\text { Thailand, Lithuania, Latvia, South Central } \\
\text { Europe, Russian Fed., Tunisia, Iraq, Jordan, } \\
\text { Iran, Algeria, Namibia, Oceania Islands }\end{array}$ & $3 \cdot 00-1 \cdot 50$ & $520 \cdot 0$ & 0.69 & $3 \cdot 5$ & 1.85 \\
\hline 3 & $\begin{array}{l}\text { Egypt, Morocco, Syria, Swaziland, } \\
\text { Cape Verde, Eq. Guinea, Albania, } \\
\text { Bosnia/Herzegovina, Paraguay, Ecuador, } \\
\text { Bolivia, Honduras, Kazakhstan, Turk- } \\
\text { menistan, Sri Lanka, Philippines, China, } \\
\text { Pap. Guinea, Ocean Islands }\end{array}$ & $1.50-0.75$ & $1547 \cdot 0$ & 0.75 & $4 \cdot 1$ & $0 \cdot 90$ \\
\hline 2 & $\begin{array}{l}\text { CIS-countries, Côte de Ivory, Congo, } \\
\text { Cameroon, Lesotho, Senegal, Zimbabwe, } \\
\text { Guinea, Indonesia, Pakistan, India, Haiti, } \\
\text { Nicaragua }\end{array}$ & $0.75-0.40$ & $1568 \cdot 0$ & 1.22 & $3 \cdot 9$ & 0.49 \\
\hline 1 & $\begin{array}{l}\text { Vietnam, Bangladesh, Myanmar, Laos, } \\
\text { Cambodia, Nepal, Mongolia, Kyrgyzs- } \\
\text { tan, Tajikistan, Yemen, Afghanistan, } \\
\text { Sub-Sahara, Central-South, East African } \\
\text { countries }\end{array}$ & $0<0.40$ & 893.5 & $2 \cdot 36$ & $2 \cdot 9$ & 0.27 \\
\hline
\end{tabular}

national income per capita with motorization and road fatality rates (per motor vehicles) for recently estimated data for groups of countries with similar income levels, as developed by Koornstra (2002a). Economic growth inevitably stimulates the growth of motorization levels (motor vehicles per inhabitant, including 2- and 3-wheel motor vehicles). The higher the gross national income per capita $(\mathrm{GNI} / \mathrm{p})$ the higher the motorization level is, while the fatality rate per number of motor vehicle decays over time (Oppe \& Koornstra 1990) and generally, thus, also with growth of GNI/p. In order to obtain functions of GNI/p for motorization level and fatality rate, the countries with a similar GNI/p are grouped into eight country categories within successive ranges of GNI/p, as shown in table 1 . This Table shows the countries contained in each GNI/p-category, the population totals for these categories in 2000, their estimated averages of annual population and GNI/p growth percentages between 2000 and 2015, and their average GNI/p levels in 2000 [GNI/p data and growth rates: WB (2003); population data and growth rates: UN (2002)]. 


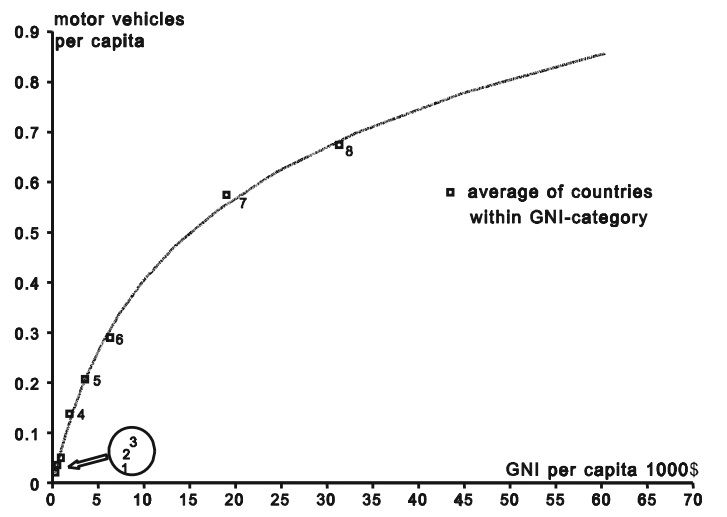

Figure 10. Relationship of motorization $\left(M_{j}\right)$ with $\mathrm{GNI} / \mathrm{p}\left(G_{j}\right)\left(M_{j}=0 \cdot 24 \cdot \ln [3 \cdot 25+\right.$ $\left.\left.\left(G_{j} / 1000\right)^{1 \cdot 15}\right]-0 \cdot 28\right)$.

The motorization (motor vehicles per inhabitant), the road fatality rate (per 10.000 motor vehicles), and the rates of road injuries per fatality are calculated for the total of countries in each GNI/p category. The rates for countries where fatality, injury, and or traffic volume data are missing (for example Turkey, China, several African and South-East Asian countries), or are incomplete (for example Mexico, Brazil), or are inconsistent over time (for example Peru, Thailand), or inconsistent with other data (for example: a few middle and low income countries reporting much lower fatality rates per motor vehicle than highly motorized countries) are estimated by the average of other countries in the same region and same GNI/p category as the country with missing data (data sources for road traffic death and injuries and motor vehicles: IRF (2002), OECD-IRTAD (2002), Jacobs et al (2000); a data summary is given in Koornstra, 2002a). Figures 10 and 11 show the obtained motorization levels and fatality rates per 10,000 motor vehicles for the country categories in 2000 as well as the curved relationships of GNI/p with motorization level and fatality rate.

The product of relationships in figures 10 and 11 defines the road traffic mortality as a function of the GNI/p. Figure 12 shows the single-peaked function of GNI/p for mortality (road traffic deaths per 100.000 inhabitants). Notice that the single-peaked function for mortality could not have been well determined without the underlying monotone functions of GNI/p for motorization and fatality rate. The averages of the actual mortality levels for the country categories are also shown in figure 12.

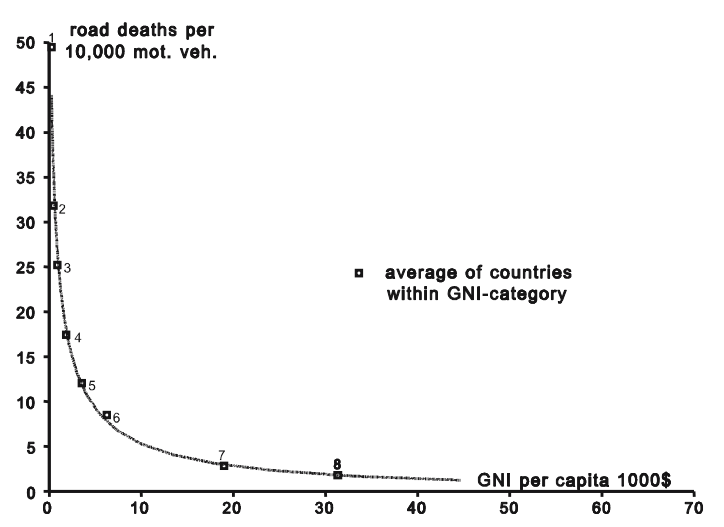

Figure 11. Relationship of fatality rate $\left(R_{j}\right)$ with $\mathrm{GNI} / \mathrm{p}\left(G_{j}\right)\left(\ln \left(R_{j}\right)=-3.94\right.$. $\ln \left[2 \cdot 10\left(G_{j} / 1000\right)^{0.40}+7 \cdot 69\right)$. 


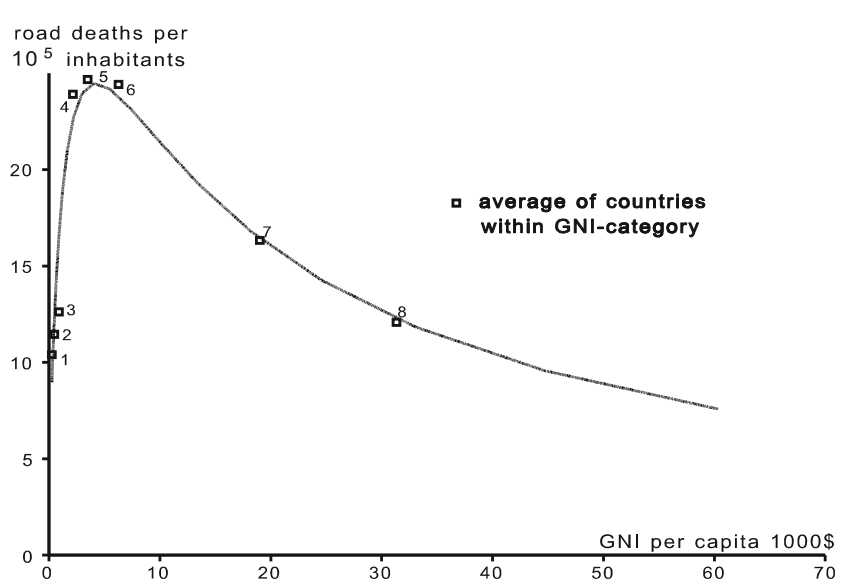

Figure 12. Relationship of roadtraffic mortality with GNI/p.

Increased levels of GNI/p from above 5,000 US\$ relate to decreases of road traffic mortality, despite their correspondingly increasing motorization. However, a sharply increasing road traffic mortality is observed for increases of GNI/p below the GNI/p-level of US $\$ 3,500$ as applies to the lowest income countries (category 1 ) to the highest lower-middle income countries (category 4), while their corresponding motorization also increases. By the population volumes of the country categories in table 1 and their mortality values in figure 12 one obtains the estimated road traffic deaths of the country categories. They accumulate to 877 thousand deaths worldwide (police-reported or estimated) for the year 2000 .

\section{Estimations for 2000 corrected for under-reporting}

The recent studies on traffic fatalities worldwide estimate 633 thousand fatalities (Kopits \& Cropper 2005), between 750 and 880 thousand fatalities (Jacobs et al 2000), and 1.17 million fatalities (Krug 1999). Kopits and Cropper did not correct for differences in definition of road death (within 30 day after the crash), or for under-reporting, but they corrected for missing data by using continent rates for missing countries. Jacobs et al corrected for the 30 day definition of road fatalities and for missing data by using continent rates, and gave a range for totals in 1996 by assuming no more than $15 \%$ for under-reporting. Using continent rates for countries with missing data not only gives less reliable estimates than estimation by average rates of countries with similar income levels in the same continent (fatality rates of countries in the same continent vary much more), but it also gives under-estimates by not correcting for countries with incomplete or inconsistent data. Only the WHO-study of Krug (1999) is based on national hospital surveillance registrations of deaths caused by road traffic in 1998/1997. This means that the actual road traffic deaths in the world are most likely about 1.2 million, whereby our estimated 877 thousand fatalities are most likely the result of under-reporting by $27 \%$ of the total. That percentage actually will be lower in medium-high income countries and higher in low income countries, because the police generally under-reports the road traffic deaths more in middle and low income than in high income countries. The estimated deaths, therefore, must additionally be adjusted differently for the country categories from mediumhigh to low income countries, because the data are already adjusted for the actually researched under-reporting in the highest income countries. 


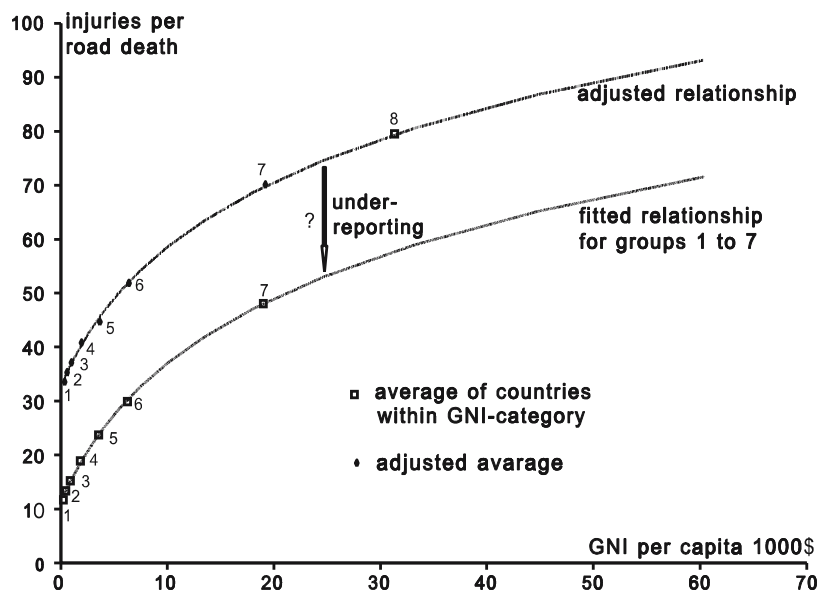

Figure 13. Relationship of GNI/p $\left(G_{j}\right)$ with injuries per death $\left(I_{j} / F_{j}\right)$.

Road traffic not only causes deaths, but also injuries. In figure 13 we show the relationship of GNI/p with road traffic injuries per death, as obtained from our data gathering and estimation for countries with missing, incomplete, or inconsistent data. Figure 14 displays the relationship of GNI/p with road traffic injury rate per 1,000 inhabitants, as derived from the multiplied functions of figure 13 and 12. The injuries in some countries of category 8 with the highest GNI/p are well reported or are corrected in advance by factors derived from national comparisons with hospital surveillance registration data (OECD-IRTAD, 1994). In countries with a lower GNI/p the under-reporting degree of road injuries is unknown, but is estimated to be about $30 \%$ for serious injuries in European high income countries of category 8 . Therefore, a prior correction of reported injuries per death by factor of 1.4 has been initially used for all injuries in country groups 1 to 7 . As figure 13 shows, this still yields a systematic under-reporting, because the well fitting relationship for categories 1 to 7 underestimates the correct injuries per death for countries in the highest GNI/p category.

The upward displaced function curve for categories 1 to 7 that passes through the value for category 8 , is assumed to describe the actual relationship. This would mainly correct for

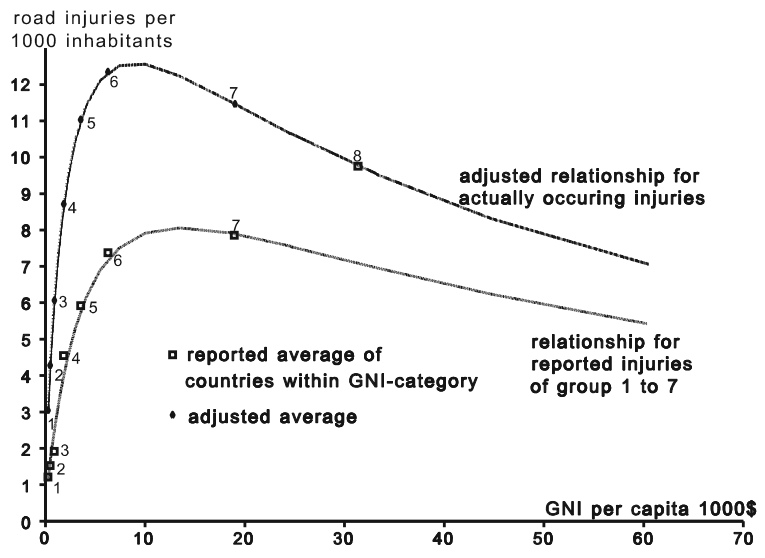

Figure 14. Relationship of injury rate with GNI/p. 
Table 2. Deaths, serious injuries and minimum and maximum, slight injuries in 2000.

\begin{tabular}{lccccccc}
\hline & $\begin{array}{c}\text { Deaths } \\
\text { Group }\end{array}$ & $\begin{array}{c}\text { Adjusted } \\
\text { deaths }\end{array}$ & $\begin{array}{c}\text { Serious } \\
\text { injuries } \\
\text { million }\end{array}$ & $\begin{array}{c}\text { Minimum } \\
\text { slight inj. } \\
\text { million }\end{array}$ & $\begin{array}{c}\text { Maximum } \\
\text { slight inj. } \\
\text { million }\end{array}$ & $\begin{array}{c}\text { Minimum } \\
\text { victim tot. } \\
\text { million }\end{array}$ & $\begin{array}{c}\text { Maximum } \\
\text { victim tot. } \\
\text { million }\end{array}$ \\
\hline 8 & 7,000 & 76 & 1.44 & 4.63 & 4.63 & 6.15 & 6.15 \\
7 & 40 & 45.5 & 0.52 & 1.40 & 2.27 & 1.96 & 2.84 \\
6 & 62 & 76 & 0.60 & 1.26 & $2 \cdot 61$ & 1.92 & 3.29 \\
5 & 104 & 133 & 0.89 & 1.58 & 3.84 & 2.57 & 4.87 \\
4 & 125 & 170 & 0.98 & 1.38 & 4.11 & 2.49 & 5.26 \\
3 & 194 & 279 & 1.43 & 1.53 & 5.75 & 3.15 & 7.46 \\
2 & 181 & 272 & 1.30 & 1.13 & 5.07 & 2.61 & 6.64 \\
1 & 94 & 148 & 0.66 & 0.43 & 2.48 & 1.19 & 3.30 \\
total & 877 & 1200 & 7.84 & 13.34 & 30.77 & 22.05 & 39.81 \\
\hline
\end{tabular}

under-reporting of slight injuries per death, because all original injuries per death are already corrected for $30 \%$ under-reporting of serious injuries in high income countries. Therefore, in figure 14 two estimates of injury rates are derived: one for the original values and the other for the adjusted values of figure 13 . The adjusted function curve for the injury rate (per 1,000 inhabitants) initially increases with GNI/p (also with motorization level), but decreases with increases of GNI/p level above US\$10,000 (despite the correspondingly increasing motorization levels).

The injuries per death decrease with GNI/p the lower the income level of countries is, due to their low level of motorization and high shares of motorized 2- and 3-wheel vehicles with higher fatal risks than motorized 4- or more-wheel vehicles (motorized 2- and 3-wheel vehicle shares range from $25 \%$ for category 5 to $50 \%$ for category $2+1$, while low income parts of South-East Asia have shares of over 80\%). This also results in larger shares of road crashes between 4-(or more) wheel motor vehicles and vulnerable road users (pedestrians, cyclists, mopedists, motorcyclists, rickshaw occupants) with relatively more fatal and less injury outcomes. The populations (table 1), the function values of figure 12, and the two function values in figure 14 yield estimates of the estimated, police reported and adjusted fatalities and minimum and maximum injuries in 2000 , as given in table 2 . The difference between the maximum and minimum injuries is mainly caused by the under-reporting of slight injuries, because the minimum estimates of injuries are only corrected for $30 \%$ under-reporting of the serious injuries. Assuming a proportional relationship between under-reporting of injuries and fatalities, the adjusted fatalities become corrected for under-reporting by almost $31 \%$ of the estimated under-reporting proportions of injuries, yielding 1.2 million deaths. It means that about $12 \%$ under-reporting of deaths in the medium-high income country category 7 to almost $36 \%$ in the lowest income country category 1 . The $12 \%$ under-reporting in category 7 is in accordance with research results for several countries in that category (research by INRETS for road deaths in the region of Lyon yields 12\% under-reporting; Jacobs et al (2000) mention that reported road deaths in Italy are $26 \%$ lower than the hospital surveillance data from the WHO, whereof $14 \%$ is already incorporated by our adjustment from the Italian 7 day to the 30 day definition), showing some evidence for the validity of these differential fatality adjustments. The serious injuries in table 2 are estimated by 3 times the adjusted fatalities plus $20 \%$ of the minimum injuries, as this holds for the EU (ETSC, 1997) and USA.

The annual number of life-long completely disabled road victims (in average living 32 years after their disablement) can be estimated as almost one third of the annual fatalities 
(Murray et al 1993). About twice are probably semi-disabled (in average living 32 years $50 \%$ disabled), while the average period of temporary disability for each of the remaining 6.1 million serious injuries in 2000 will be at least half a year. Thereby, we estimated that the disability-adjusted life years (Daly's) lost by the 7.84 million serious injuries are about $86 \%$ of the expected life years lost by the 1.2 million deaths in 2000 , whereby the Daly's lost by road traffic becomes revised for 2000 to:

$$
\begin{gathered}
1.86(=\text { multiplication factor }) \times 1.2(=\text { million of deaths }) \\
\times 32(=\text { expected life years })=71.4 \text { million }
\end{gathered}
$$

This estimate of Daly's lost by road traffic compared to the (unchanged) Daly's lost by other causes (Krug, 1999) means that road traffic is most likely the $5^{\text {th }}$ leading cause of the burden of disease in 2000.

\section{Predictions up to 2050}

Road fatalities have decreased only in high income countries and semi-motorized, uppermiddle income countries, as shown earlier, but the global road fatalities are increasing over the last two decades. In motorizing middle and low income countries there were over $50 \%$ more road traffic deaths in 2000 than in 1980. The situation is even worse for the trend in road injuries. An increasing global trend can be expected over the coming years. Firstly, because the middle and low income countries have higher population growth percentages and mostly also higher road traffic mortality and injury rates (per amount of inhabitants) than high income countries. Secondly, because the lower-middle and low income countries will also show an increase of mortality and injury rates, due to growth of their GNI/p and the relationship of GNI/p with mortality and injury rates (figures 12 and 14). Thirdly, because the upper-middle, some developing lower-middle, and a few developing upper-low income countries are also motorizing rapidly. Thus, it can be expected that the road fatality reductions in higher income countries don't compensate for fatality increases in lower-middle and low income countries in the coming decade. This is indeed the outcome of prognoses (Koornstra (2002a, b) based on the assumptions that:

(i) the relationships of GNI/p with motorization level, road traffic deaths per motor vehicle, and injuries per death (shown in figures 10,11 and 13) will continue to hold in the future; (ii) populations grow by their recently reduced predictions of annual growth percentages by the UN (percentages for 2000 to 2015 also listed in table 1); (iii) the annual growth of GNI/p will in average be $4 \%$ from 2000 to 2030 for all country groups.

Table 3 summarizes the predicted fatalities and serious injuries for 2020, 2030, and 2050 (including corrections for their respective under-reporting by the police), based on the prognosis model of Koornstra (2002a) using 4\% annual increase of GNI/p to 2050 and the diminishing population growth percentages to 2050 according to the UN (2002). Comparing the prognosis with the estimation for 2000 the trend in fatalities is decreasing for high income countries (category 8 and 7), as it has been in the last three decades of the $20^{\text {th }}$ century. For the upper-middle income countries the numbers of fatalities and serious injuries are only predicted to decrease after 2015 for country category 6 and after 2025 for country category 5 . There is also a decrease in the higher income category 4 of the lower-middle income countries after 2035. Up to these successive turning points in time for the respective country categories 6,5 , and 4 their respective road mortality reductions (predicted by figure 12 from their 
Table 3. Initial prognoses of deaths and serious injuries in 2020, 2030, and 2050.

\begin{tabular}{|c|c|c|c|c|c|c|}
\hline \multirow[b]{2}{*}{ Groun } & \multicolumn{3}{|c|}{ Deaths $\times 1000$} & \multicolumn{3}{|c|}{ Million serious injuries } \\
\hline & 2020 & 2030 & 2050 & 2020 & 2030 & 2050 \\
\hline 8 & 47 & 34 & 16 & 1.03 & 0.82 & 0.45 \\
\hline 7 & 28 & 21 & 10 & 0.41 & $0 \cdot 34$ & 0.20 \\
\hline 6 & 73 & 65 & 42 & 0.75 & 0.76 & 0.62 \\
\hline 5 & 146 & 138 & 99 & 1.25 & $1 \cdot 34$ & 1.23 \\
\hline 4 & 193 & 189 & 151 & $1 \cdot 35$ & $1 \cdot 50$ & 1.54 \\
\hline 3 & 457 & 517 & 522 & 2.67 & $3 \cdot 31$ & $4 \cdot 20$ \\
\hline 2 & 471 & 577 & 684 & 2.46 & $3 \cdot 21$ & 4.58 \\
\hline 1 & 333 & 484 & 747 & 1.57 & 2.38 & $4 \cdot 20$ \\
\hline total & 1,747 & 2,026 & 2,271 & 11.49 & 13.67 & 17.02 \\
\hline
\end{tabular}

increased GNI/p) are not large enough to compensate the population growth in the product of population and mortality rate that defines the road fatalities. Successively later road fatality peaks for these country categories that become semi-motorized is in accordance with the expectation of the time series model of S-shaped traffic growth and exponential risk decay, but that model would likely locate their fatality peaks earlier.

Since the GNI/p based model seems valid for high income countries, Koornstra (2002a,b) has conjectured that it may also hold for lower-middle and low income countries. However, the model validity for the high income countries may only hold if their annual GNI/p growth percentage is indeed $4 \%$ or higher. With $4 \% \mathrm{GNI} / \mathrm{p}$ growth the predicted 55,000 fatalities in high income countries (categories $8+7$ ) for 2030 is already rather high, because as discussed earlier the more reliable time series model predicts for these high income countries about 42,000 fatalities in 2030 (after adjustment for under-reporting in category 7). Also the time series model and /or observed fatality trends for the upper-middle income countries suggests that the decrease of road fatalities will start earlier than predicted in table 3 (respectively for category 6 and 5 not around 2015 and 2025, but respectively before 2000 and 2005). Moreover, if instead of model assumption 3 different GNI/p growth percentages for 2000-2015, derived from the World Bank prospects (WB, 2003; summarized in table 1), are used in the model predictions for 2030, then the prognoses are 97,000 and 244,000 road fatalities respectively the high and upper-middle income countries (respectively category $8+7$ and $6+5$ ), due to their markedly lower projected GNI/p growth than $4 \%$ per year. Thus, on the one hand, we have for the GNI/p based model predicted fatality reduction between 2000 and 2030 of only 24,500 for high income countries and even a predicted fatality increase from 2000 to 2030 of 34,000 for upper-middle income countries, which is very unlikely in view of the more reliable predicted trends by the time series model. On the other hand, the different GNI/p growth percentages of the WB are more acceptable than the unrealistically equal $4 \%$ for each country group. This leads to the conclusion that if the different GNI/p growth percentages hold, then the assumption one (i) of constant relationships in figure 10 or 11, and thus in figure 12, must be rejected.

Given the fact that the fatality rate in high income countries has been decreasing annually by $2.75 \%$ more than predicted by the GNI/p-based model with the different GNI/p growth percentages of the WB, it most likely holds that the relationship between GNI/p and fatality rate in figure 11 is not constant, but decreases over time; by as much as $2.75 \%$ per year. The observed fatality risk decay of almost $5 \%$ per year in high income countries would 
then derive for about one halve from the GNI//p-dependent road safety improvements and for about the other halve from time-dependent road safety improvements. The question is whether assumption one (i) can be adjusted by taking for granted that the same time-dependent additional reduction of the fatality rate also applies to middle and low income countries. This most likely is not the case, because if the GNI/p-based model is adjusted by an overall additional reduction of $2.75 \%$ per year than the global fatalities are predicted to decrease now, which is not the case. Moreover, the road safety in high income countries concerns mainly vehicle occupants of car crashes, while the road safety of lower-middle and low income countries is dominated by crashes with pedestrians, bicyclists and motorized 2-and 3-wheel vehicles (over $50 \%$ in many low income countries) with much higher fatal crash risks than for car occupants (to over 20 times). Therefore, we have to adjust the GNI/p-based prognosis model of Koornstra (2002a) not only by a differentiated GNI/p growth, but also by either:

(i) an annual fatality rate reduction of $2.9 \%$ that is multiplied by the proportion of 4 - and more-wheel motor vehicles of all motor vehicles in each income category of countries, or

(ii) an annual fatality rate reduction of $3.4 \%$ that is multiplied by the level of motorization in each income category of countries.

For the first adjustment we need not only the GNI/p-based prediction of motor vehicles (by the function of figure 10 and UN-population forecasts), but also predicted 2/3-wheel motor vehicle proportions by the well fitting function:

$$
P_{j}=\operatorname{Exp}\left\{-0.572 \cdot \ln \left[1+\left(G_{j} / 1000\right)\right]-0 \cdot 680\right\}
$$

with $G_{j}$ as $\mathrm{GNI} / \mathrm{p}-\mathrm{level}$.

The GNI/p-based model of Koornstra (2002a) is adjusted in two related ways:

(a) instead of $4 \%$ annual GNI/p growth for all income categories of countries, the annual GNI/p growth percentages as projected to 2015 by the WB and summarized in table 1 are used for predictions after 2015; and

(b) instead of the constant relationship between GNI/p level and fatality rate given in figure 11, an annually reducing relationship is used, where the reduction percentage per country category equals:

(b1) $2.9 \%$ times the predicted proportion of 4-(and more-)wheel motor vehicles, or

(b2) equals $3.4 \%$ times the predicted motorization level.

The prediction model based on (a) and (b1) is called the reference model (prediction formulae in bottom note $*$ ) and the model based on (a) and (b2) the alternative reference model (prediction formulae in bottom note $* *$ ). The fatality, serious injury and total victim predictions for the reference and alternative reference models are given in table 4 .

The time- and GNI//p-dependent reference model and the alternative reference models predict respectively 42,000 and 43,000 road fatalities in 2030 for high income countries (category $8+7)$ as also predicted by the time series models of Gompertz traffic growth and exponential risk decay. This is because the magnitude of the additional time-dependent reduction of the relationship between fatality rate and GNI/p in the reference and alternative reference models was chosen to achieve forecasts that for the highest income countries (category 8 only) are identical to its time series model prediction. However, the predicted road fatality reductions for 2030 by the reference model from 76,000 to 38,000 in category 6 and from 133,000 to 75,000 in category 5 of the upper-middle income countries are more in line with the time 
Table 4. Adjusted prognoses of deaths and injuries in 2030.

\begin{tabular}{|c|c|c|c|c|c|c|}
\hline Group & $\begin{array}{c}\text { GNI/p } \\
1,000\end{array}$ & $\begin{array}{l}\text { pop. } \\
\text { million }\end{array}$ & $\begin{array}{l}\text { Deaths*) } \\
1,000 \\
\text { reference } \\
\text { model }\end{array}$ & $\begin{array}{l}\text { Ser. inj. } \\
\text { million } \\
\text { reference } \\
\text { model }\end{array}$ & $\begin{array}{c}\text { Deaths } * *) \\
1000 \\
\text { alternative } \\
\text { ref. model }\end{array}$ & $\begin{array}{l}\text { Ser. inj } \\
\text { million } \\
\text { alternative } \\
\text { ref. model }\end{array}$ \\
\hline 8 & 48.97 & 713 & 27 & 0.56 & 27 & 0.56 \\
\hline 7 & 32.48 & 260 & 15 & 0.20 & 16 & 0.22 \\
\hline 6 & $11 \cdot 70$ & 340 & 38 & 0.37 & 55 & 0.53 \\
\hline 5 & 7.90 & 565 & 75 & $0 \cdot 64$ & 110 & 0.94 \\
\hline 4 & $5 \cdot 18$ & 631 & 93 & 0.70 & 145 & $1 \cdot 10$ \\
\hline 3 & 2.99 & 1,890 & 263 & 1.69 & 436 & $2 \cdot 81$ \\
\hline 2 & 1.56 & 2,193 & 323 & 1.79 & 514 & $2 \cdot 85$ \\
\hline 1 & 0.63 & 1,772 & 249 & $1 \cdot 18$ & 407 & 1.94 \\
\hline Total & $13 \cdot 64$ & 8,363 & 1,082 & $7 \cdot 14$ & 1,710 & $10 \cdot 94$ \\
\hline
\end{tabular}

series model forecasts than the predictions by the alternative reference model. For the lowermiddle income countries only the higher income category 4 shows a road fatality prediction that markedly decreases from 170,000 in 2000 to 93,000 in 2030 in the reference model, where the decrease actually occurs after an initial increase till the year 2005. This could also be in line with the expectation that the somewhat later motorization evolution in most countries of category 4 and 5 will also lead to a somewhat later road fatality peak for these countries of category 4 and category 5 . The time- and GNI/p-dependent model predictions of the reference model contains a better extrapolation of present trends than the GNI/p-dependent model or the alternative reference model. Therefore, the reference model also may have higher prediction validity for the other lower-middle and low income country categories, wherein the road fatalities hardly decrease in 2030 for category 3 of the lower-middle income countries and increase in 2030 by $19 \%$ and $68 \%$ respectively for categories 2 and 1 of the low income countries in comparison to the year 2000. Same points hold good for the reference model with respect to under-reporting-adjusted serious injuries. Thus, it is concluded that the road deaths and serious injuries will rise in developing countries and dramatically so in low income countries, if presently existing trends for GNI/p growth and time-dependent risk reduction of 4-(and more-)wheel traffic are extrapolated.

*) Under-reporting adjusted fatalities: $F_{j}=I_{j} \cdot M_{j} \cdot \operatorname{Exp}\left\{-3 \cdot 94 \cdot \ln \left[2 \cdot 10+\left(\mathrm{GNI}_{j} / 1000\right)^{0 \cdot 4}\right]+\right.$ $7.69\} \cdot[1-0.029 \cdot(1-P j)]^{y}$

for category $j$ with forecasts $G_{j}$ of GNI/p, $I_{j}$ of inhabitants, and $M_{j}$ of motorization by function of figure 10, and where $P_{j}$ is the proportion of 2/3-wheel motor vehicles and $Y$ the years of the prediction period.

**) Under-reporting adjusted fatalities

$$
\begin{aligned}
F_{j}= & I_{j} \cdot M_{j} \cdot \operatorname{Exp}\left\{-3.94 \cdot \ln \left[2 \cdot 10+\left(\mathrm{GNI}_{j} / 1000\right)^{0 \cdot 4}\right]+7 \cdot 69\right\} \\
& \times[1-0.034 \cdot(1-M j)]^{y}
\end{aligned}
$$

for category $j$ with forecasts $G_{j}$ of GNI/p, $I_{j}$ of inhabitants, and $M_{j}$ of motorization by function of figure 10 for prediction period with y years. 


\section{The potential of future risk reductions in developed countries}

\subsection{Road infrastructure safety improvements}

Road users are not less or more responsible on different road types, but road risks differ markedly, dependent on the traffic complexity created by the road type and its allowed road modes, as shown for Germany and the Netherlands in table 5 below. This Table shows that speed kills not primarily, because the lowest fatality risks are in traffic calming areas $(30 \mathrm{~km} / \mathrm{h}$ limit) and on motorways (100/120 km/h limit in Netherlands or no limit in Germany). On these road types the speed deviations between its road users are proportionally smaller than on other road types. The injury risk is highest on roads where relatively high differences in speed and direction are present in combination with moderate speed limits $(50$ or $70 \mathrm{~km} / \mathrm{h}$ limit, mixed slow and fast traffic, level crossings, opposite traffic). The fatality risk is highest where also the speed limits are inappropriately high (e.g. the 80 or $100 \mathrm{~km} / \mathrm{h}$ limits on roads with mixed traffic, level crossings, and opposite traffic without mid barriers).

Clearly the infrastructure design and traffic rules of roads determine the traffic complexity for its road users and, thereby, also the risk differences between road types. These differences are mainly explained by effects of different average impact speeds in crashes, especially in crashes with pedestrians or cyclists, and by effects of speed differences on crash frequency.

Figure 15 explains why slow traffic should never be mixed with relatively fast motor traffic or should never cross roads if motor vehicles drive faster than $30 \mathrm{~km} / \mathrm{h}$.

Figure 16 clearly demonstrates that the effect of speed above the average is quadratic related to crash involvements on main rural roads and expressways. Although, the older results from USA (Warren, 1982) differ for speeds that are below average from the recent research in the UK (Taylor et al 2000, 2002). Moreover, the probability of a fatal outcome of a crash has a quadratic relationship with collision speed itself. The crash probability on a road type also depends on the average vehicle speed by the dependence of crash avoidance (reaction time, braking distance, and steering control) on the speed driven and on the probability of a traffic conflict. The traffic conflict probability depends mainly on speed differences that cause overtaking manoeuvres, rear end conflicts, and increased traffic complexity for other road users. Since speed differences generally increase proportionally with the average speed a proportional change in average speed relates by a power of four to a proportional change in fatalities (e.g. a speed reduction by $7 \%$ results on average in a fatality reduction factor of $\left(0.93^{2}\right)^{2}=0.75$ or $\left.25 \%\right)$, which is illustrated in figure 17 . This fits the observed road safety

Table 5. Risks per vehicle kilometres on road types in Netherlands 1994 and Germany 1993.

\begin{tabular}{|c|c|c|c|c|c|c|c|c|}
\hline \multirow{2}{*}{$\begin{array}{l}\text { Road } \\
\text { Type }\end{array}$} & \multicolumn{2}{|c|}{$\begin{array}{l}\text { Speed } \\
\text { limit }\end{array}$} & \multirow{2}{*}{$\begin{array}{l}\text { Mix } \\
\text { fast/ } \\
\text { slow }\end{array}$} & \multirow{2}{*}{$\begin{array}{c}\text { Crossing/ } \\
\text { opposite } \\
\text { traffic }\end{array}$} & \multicolumn{2}{|c|}{$\begin{array}{c}\text { Injury rate } \\
10^{6} \mathrm{~km}\end{array}$} & \multicolumn{2}{|c|}{$\begin{array}{c}\text { Fatality rate } \\
10^{8} \mathrm{~km}\end{array}$} \\
\hline & Neth. & Ger. & & & Neth. & Ger. & Neth. & Ger. \\
\hline Calming area & 30 & - & yes & yes & $0 \cdot 20$ & - & $0 \cdot 3$ & - \\
\hline Residential roads & 50 & 50 & yes & yes & 0.75 & $1 \cdot 75$ & $1 \cdot 0$ & 1.7 \\
\hline Urban arteries & $50 / 70$ & $50 />50$ & yes/no & yes & $1 \cdot 33$ & $1 \cdot 37$ & $2 \cdot 3$ & $2 \cdot 1$ \\
\hline Rural roads & 80 & 100 & yes & yes & 0.64 & & $3 \cdot 6$ & \\
\hline Rural arteries & 80 & 100 & no & yes & $0 \cdot 30$ & $0 \cdot 4$ & 1.8 & $2 \cdot 8$ \\
\hline Rural motor roads & 100 & 100 & no & yes/no & 0.11 & $0 \cdot 26$ & $1 \cdot 0$ & 0.8 \\
\hline Motorways & $100 / 120$ & no & no & no & $0 \cdot 07$ & $0 \cdot 15$ & 0.4 & 0.5 \\
\hline
\end{tabular}



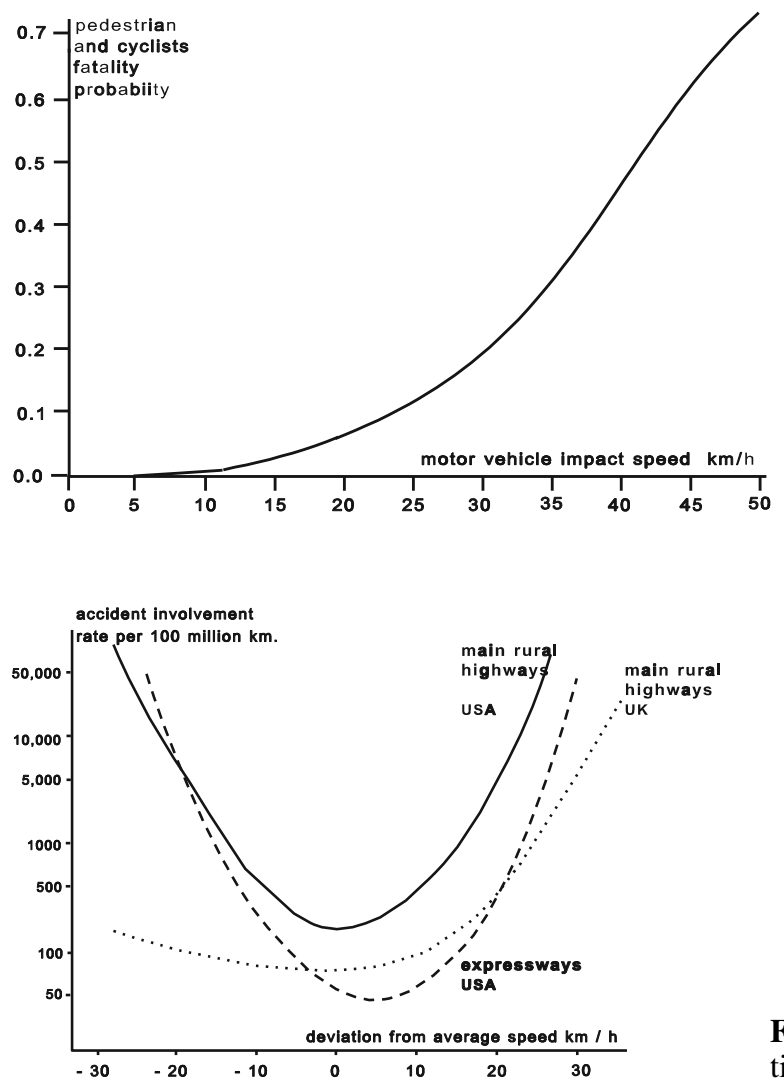

Figure 15. Pedestrian/cyclist fatality probability as function of impact speed.

Figure 16. Crash involvement rate as function of motor vehicle speed differences.

effects from speed reductions after lowered speed limits or intensified speed limit enforcement on several road types (from motor ways to residential roads) in many countries. Since this relationship is almost fully determined by physical laws, it is astonishing that speed limits on motorways are still lacking or rather high in some countries and that still many nations have

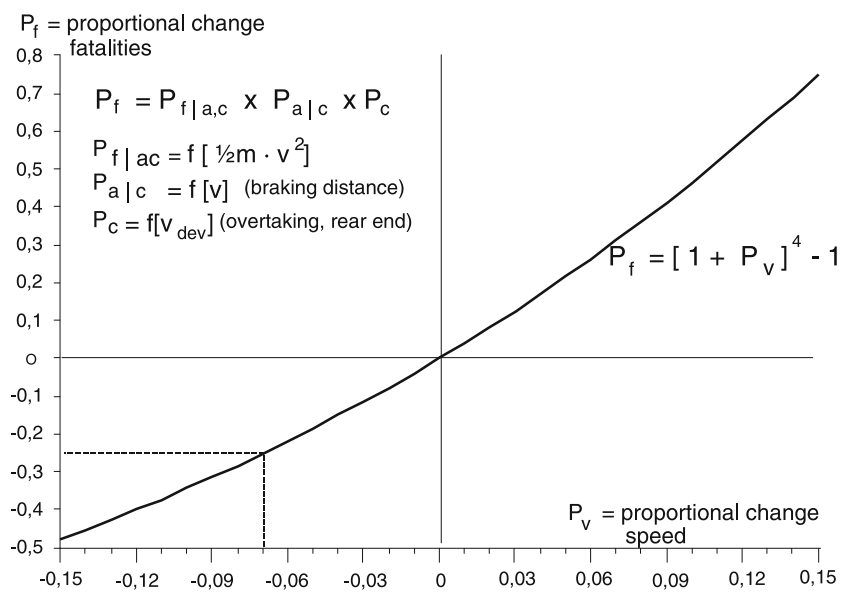

Figure 17. Dependence between proportional speed and fatality changes. 
main rural highways with a limit of $100 \mathrm{~km} / \mathrm{h}$, which is too high for their mixture of allowed traffic.

Therefore, road safety is markedly enhanced if (i) no mixing of fast and slow traffic is allowed on roads and crossings with car speeds that are (locally) higher than $30 \mathrm{~km} / \mathrm{h}$ (only mixed traffic on $30 \mathrm{~km} / \mathrm{h}$ roads with single lane roundabouts of a $30 \mathrm{~km} / \mathrm{h}$ design for their intersections with $50 \mathrm{~km} / \mathrm{h}$ roads that have separated cycle paths in built-up areas) and elsewhere not only separated cycle paths, but also graded level crossings for cyclists and pedestrians are applied; (ii) roads with speed limits above 50 up to $80 \mathrm{~km} / \mathrm{h}$ have no level crossings for cars, but roundabouts that physically reduce the car speeds locally; (iii) mid barriers and grade separated crossings are applied on roads with speed limits higher than $80 \mathrm{~km} / \mathrm{h}$.

If such a redesign of the road infrastructure would be accomplished, then the result would be that slow traffic fatalities reduce at least by $90 \%$, while motorized road user fatalities on urban and rural roads reduce by about $80 \%$ and on motor roads (not motorways) by $60 \%$. In total about 80 to $90 \%$ fatalities could be saved by such a road infrastructure redesign. The full reconstruction is costly and will take a longer period than two decades, but many most effective and less costly redesign measures can be taken before 2020 and then could likely save at least $40 \%$ fatalities.

Figure 18 schematically presents a fully re-designed road structure for a city of 75,000 citizens, wherein we have not pictured the streets of the $30 \mathrm{~km} / \mathrm{h}$ areas that are surrounded by $50 \mathrm{~km} / \mathrm{h}$ roads with $30 \mathrm{~km} / \mathrm{h}$ roundabouts. The road design of the central schematic square in figure 18 would apply to a village of about 10,000 inhabitants. Notice that here cyclists and pedestrians never meet cars with speeds above $30 \mathrm{~km} / \mathrm{h}$ in the whole city or village, while crashes with vulnerable road users in $30 \mathrm{~km} / \mathrm{h}$ areas are hardly fatal. This road reconstruction design scheme and the application of the three road safety improvement principles discussed above are nowadays to a large extent the kernel of the sustainable-safe road transport policy of the Netherlands and also of the Swedish and Swiss vision-zero policies on road safety, but it should also be the guiding principles for the future road infrastructure development

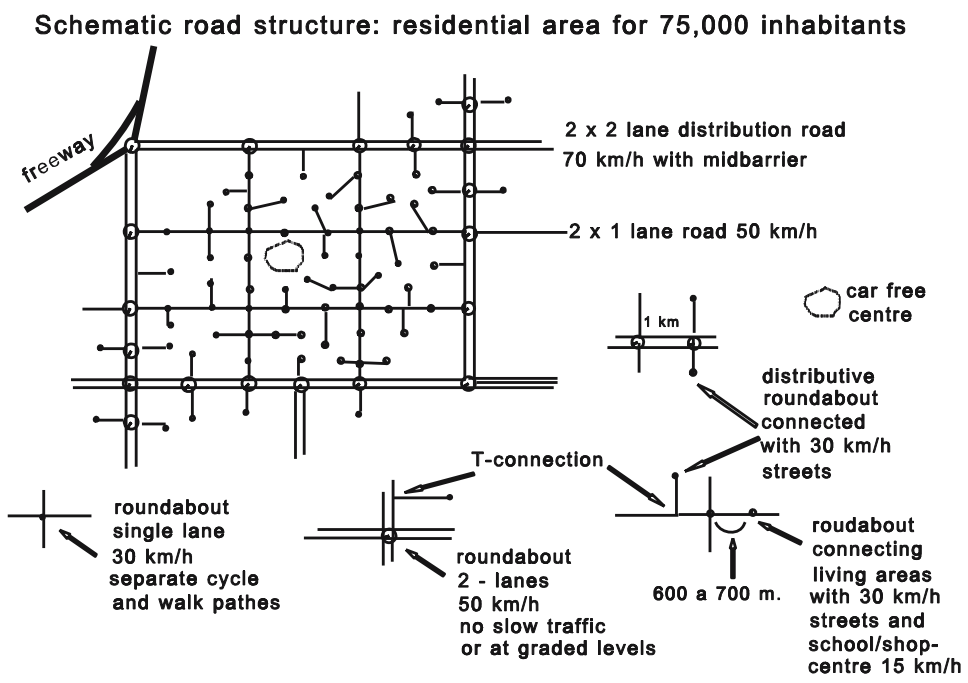

Figure 18. Schematic redesign of the road infrastructure for a city. 
and reconstructive road rehabilitation in developing countries, where the road fatalities and serious injuries involve mainly the vulnerable road users.

\subsection{Safety improvements of road user behaviour}

Not wearing seat belts by car occupants or no helmet use by (motorized) two-wheelers, drinking and driving, and speed limit violations are four behaviour types that also contribute to a high fatality risk. Effectiveness of belt wearing seems misunderstood, because frequency of seat belt use generally decreases with increased road speed limit while belt effectiveness is higher when crash impact speeds are lower as figure 19 shows (Koornstra 1994).

These curves derived from USA-data for 1980 to 1990, but nowadays belt injury prevention is highest on $50 \mathrm{~km} / \mathrm{h}$ roads and its fatality prevention is highest on roads with moderately higher speeds, because in modern cars that satisfy the NCAP-norms belt wearing generally prevent a fatality outcome of crashes with a collision speed below $65 \mathrm{~km} / \mathrm{h}$. Therefore, if speeds higher than $65 \mathrm{~km} / \mathrm{h}$ are allowed then the crash chance must be reduced by mid barriers, graded level crossings, and by intensified speed limit enforcement that reduce speed and speed differences.

The effectiveness of intensified enforcement of illegal road user behaviour is shown in figure 20 taken from the SUNflower report (Koornstra et al 2003).
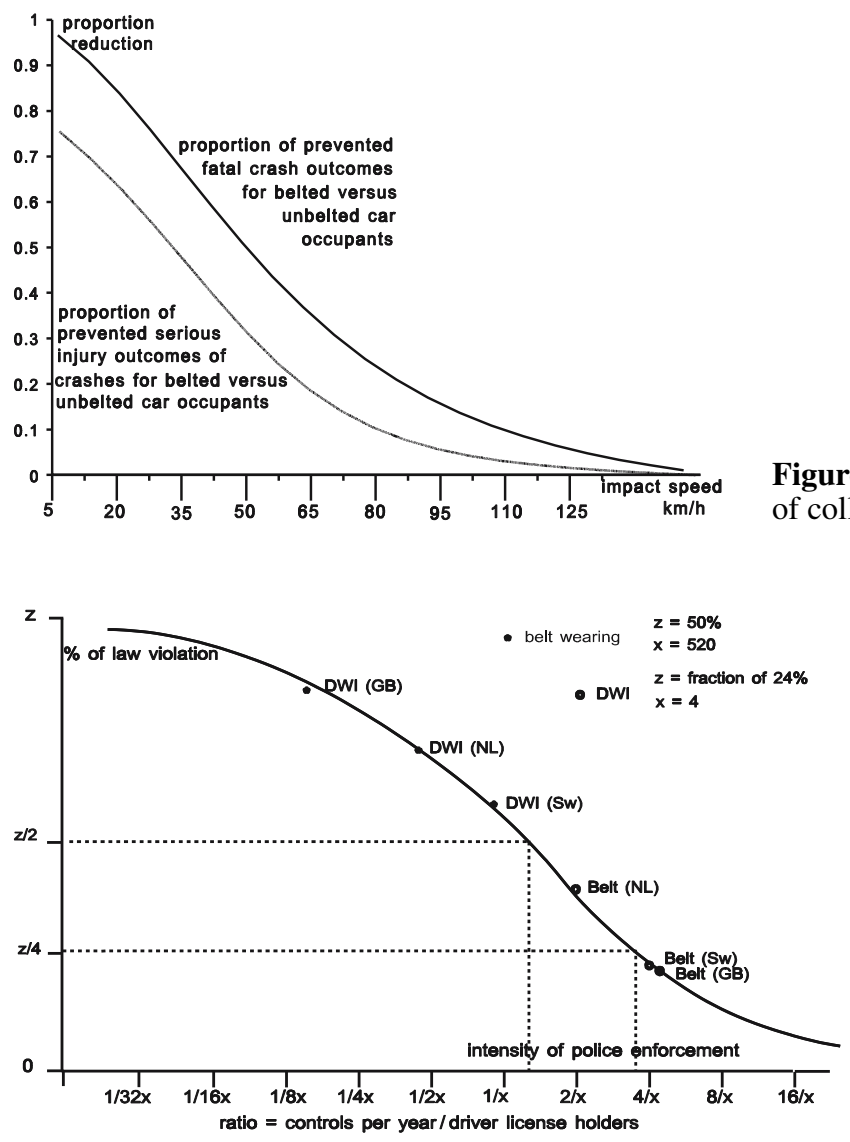

Figure 19. Belt effectiveness as function of collision impact speed.
Figure 20. Police enforcement intensity and its effectiveness. 
In this figure the empirical data for enforcement intensity on drinking and driving and on belt wearing in Sweden, the UK, and the Netherlands are plotted along the theoretical function for the reversibly S-shaped relationship between enforcement intensity (annual number of controls per license holder) and level of violations (different for different types of violations). Without police control the level of not wearing the seat belt is about 50\% (level $z=50 \%$ in figure 20 for this type of violation), but about 1 annual checking per 65 license holders (level $8 / x$ with $x=520$ for belt use controls) reduces the level of belt wearing violation to about $6 \%$. Higher belt use enforcement intensity could save more than $35 \%$ fatalities in the USA, because about $40 \%$ car occupants are unbelted in USA resulting in fact that over $60 \%$ of all US road fatalities are unbelted car occupants.

It is well known that the fatality probability increases exponentially with the blood alcohol content (BAC) of the driver. Without a noticeable police control the level of driving and drinking law violations is generally about 24\% (level $z$ for DWI in figure 20) for drivers above $0.1 \%$ BAC in weekend nights, which is then associated overall with about $40 \%$ of the national road fatalities. Most developed countries have $0.05 \%$ or $0.08 \%$ BAC laws, but if the legal BAC-level would be $0.02 \%$ (as it is in Sweden) and if its police enforcement intensity by random breath testing would be as high as 1 annual check per license holders (level 4/x with $x=4$ for DWI), then probably more than $25 \%$ road fatalities would be saved in general. This can be expected, because lack of an appropriate BAC law and insufficient DWI-enforcement in the world would likely to cause more than $33 \%$ road fatalities due to drinking and driving. However, 1 annual check per 4 license holders (the DWI-control level for Sweden) reduces fatal accidents from drinking and driving to below $12 \%$.

The average speed driven tends to be the same as the no speed limit on roads where speed limit enforcement is applied, whereby speed limits without police control are generally violated by $50 \%$ of the drivers ( $z=50 \%$ for speeding in figure 20$)$. Tentative results on effectiveness of intensified speed limit enforcement indicate that speed enforcement intensity must be increased to more than 5 checks per year per licence holder in order to reduce speed limit violations to below $10 \%$. If this could be achieved on urban arterials with limits of 50 or $70 \mathrm{~km} / \mathrm{h}$ and on main rural roads with an appropriate speed limit (preferably lowered to $80 \mathrm{~km} / \mathrm{h}$, except on rural motor roads), and if also an appropriate speed limit on motorways would be installed (preferably $100 \mathrm{~km} / \mathrm{h}$ around big cities and $120 \mathrm{~km} / \mathrm{h}$ or $130 \mathrm{~km} / \mathrm{h}$ elsewhere) and controlled, then the average speeds and speed differences would be reduced by more than $12 \%$ in the developed countries, whereby the total of the fatalities in these countries would then become reduced by about $40 \%$ or nowadays by over 40,000 in the high income countries. The effectiveness of intensified police enforcement has shown contradicting results, but as figure 20 shows if the existing control level is very low then a four-fold intensified enforcement (from 1/64x to 1/16x in figure 20) will hardly show any effect. However, if the existing enforcement level reduces already the violation level to $75 \%$ its level without controls (control level $1 / 4 \mathrm{x}$ with violation level $3 / 4 \mathrm{z}$ ) then a four-fold intensified enforcement level (to $1 / \mathrm{x}$ ) will reduce the violation level by $33 \%$ of that existing level (from $3 / 4 \mathrm{z}$ to $1 / 2 \mathrm{z}$ ). Intensified police enforcement can thus be very effective, provided that its intensity is sufficiently high. Moreover, behaviourly instructive safety information campaigns that sustain specific enforcement types have shown to increase the enforcement effectiveness. However, general safety information campaigns, road safety education and initiatives for road safety awareness have shown no or very minor road safety effects, but may be needed for the public acceptance and political priority of road safety actions.

Therefore, road safety can markedly be improved by intensified police enforcement of helmet (motor cycle and moped/mofa riders) and belt use (by drivers and by front and back 
seat passengers), and of appropriate laws on drunk driving and speed limits. Intensified police enforcement could achieve fatality reductions of $35 \%$ by use of seat belts or motorcycle helmets, $25 \%$ for drinking and driving, and $40 \%$ for speeding if appropriate limits are installed and could together reduce the fatalities by $100^{*}\left[1-(1-.35)^{*}(1-.25)^{*}(1-.40)\right]=71 \%$ in the high income countries. More than $70 \%$ fatality reduction is thus achievable within one decade by intensified enforcement and more appropriate safety device and limit laws. The investment for the needed higher enforcement level is no problem, because its costs are less than the increased public income from fines.

\subsection{Vehicle safety improvements}

Improved passive vehicle safety has probably saved about $20 \%$ fatalities in the last two decades (Broughton, 2003; Koornstra et al 2003) in the European Union. Car renewal and improved passive vehicle safety could save more than $20 \%$ up to 2020 , if in time priority would be given to new effective vehicle safety regulations, such as an automatic ignition block if some one is not belted, soft-nose car construction for vulnerable road user protection, car compatibility requirements, freight vehicle under-ride protection, etc. However, some of these regulations are not supported by car and transport industries. Also active vehicle safety regulations, if timely taken and if retrofitted, could save more than $30 \%$ fatalities. These are important vehicle regulations for devices that improve risk perception and keep drivers within the legal limits that are most effective in the short run, such as intelligent speed adaptors, automatic daytime running lights (DRL), collision avoidance assistance devices, etc. Speed adapters probably save between $20 \%$ and $40 \%$ fatalities (Varhelyi, 2002; Oei \& Polak 2002), while DRL in the EU could save about $12 \%$ fatalities. Figure 21 shows the result of a meta-analytic study on effects of DRL-use in the EU, reported to DG-TREN (Koornstra et al 1997).

The EU released a policy communication on ICT for Safe and Intelligent Vehicles (CEC, 2003). However, intelligent driving systems may only become effective in the long run. If such systems are based on communications between vehicles then they cannot be implemented in fail-safe way, because the majority of the vehicles will not be equipped in the early years of

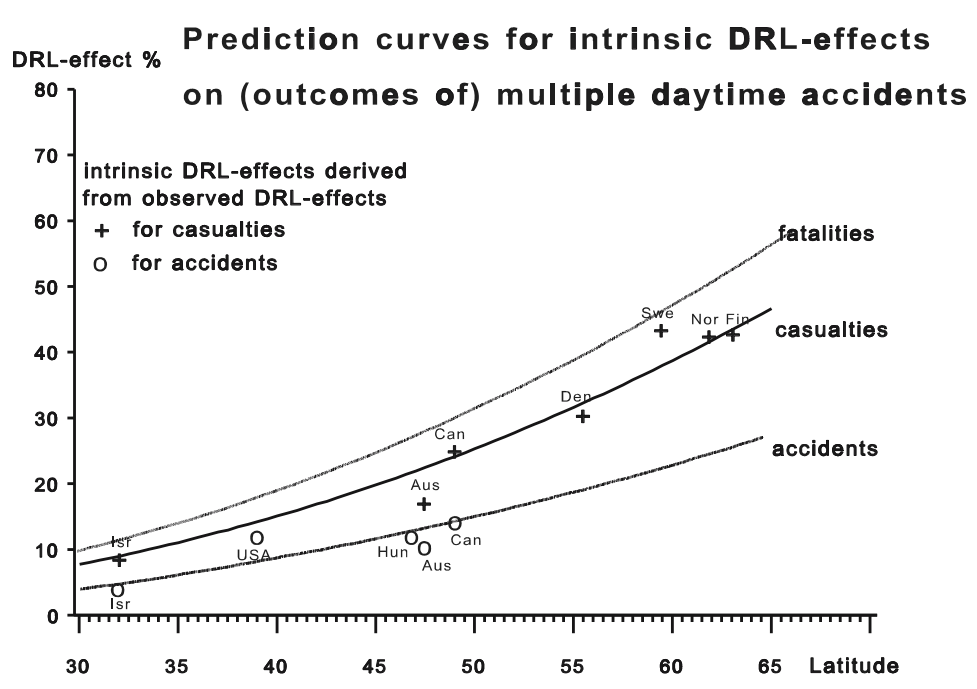

Figure 21. Effects of a DRL change from $0 \%$ to $100 \%$ as function of average country latitude. 
their introduction. Only intelligent driving systems that offer a safety surplus in the present traffic system should be supported. Research on ICT-based safety devices in vehicles and on automatic or ICT-assisted driving has been massively undertaken since 1990, but still no fail-safe and markedly safety-improving systems are developed.

The further penetration of already regulated passive safety devices and the known and available other devices for new passive and active vehicle safety regulations can together save more than $40 \%$ fatalities, but new regulations apply generally to new vehicles. Therefore, it is of utmost importance that the authorities take as soon as possible actions on new vehicle safety regulations and where possible also on their retrofitted implementations (e.g.: DRL) for the available vehicle devices that have a proven effectiveness on passive or active safety, as discussed above. However, even if such new vehicle safety regulations are taken soon and some active devices are retrofitted then they still cannot save more than $20 \%$ to $30 \%$ fatalities in 2020 .

\section{Feasibility of future risk reductions from additional safety measures}

The discussed road reconstruction, intensified police enforcement, and vehicle safety measures, when fully applied save respectively and separately about $85 \%$, about $70 \%$, and about $40 \%$ of the fatalities in the high income countries, which then together potentially could save nearly all road fatalities, because saving $100 *\left[1-(1-0.85)^{*}(1-0.7)^{*}(1-0.4)\right]=96 \%$ fatalities (correcting for fatalities already saved by another measure). However, the implementation of the road redesign measures of the recommended road infrastructure reconstruction takes time and must be financed by long term investment plans. A reduction of $70 \%$ fatalities from intensified police enforcement and adjusted limit laws is in principle achievable in a short period, but the social and political climate must change before it could be realized and realistically the required enforcement intensity may not be reached fully. Also, the realistically achievable vehicle safety measures will take time and so does the fleet renewal. Thus, the achievable risk reduction can only be realized gradually. However, it seems quite feasible that the annual risk decay in the time series model for the developed countries will indeed continue in the future, as also is required for the time- and GNI/p-dependent predictions models. The latter predictions models for the high income countries require up to 2020 only about $50 \%$ fatality risk reduction increasing to $85.5 \%$ up to 2050 with respect to 2000 , which in view of the potential to achieve a $96 \%$ fatality reduction by the proposed safety measures seems indeed quite feasible.

\section{The prevention-learning potential for less motorized countries}

The comparable road traffic risks of countries are expressed by fatality or casualty risks per amount of motor vehicle kilometres, because it is the moving motor vehicles on the roads that cause the exposure to risk for all road users. In absence of motor vehicle kilometre data these comparable risk levels are generally expressed as fatality or casualty risks per number of motor vehicles. The existing fatality risks per 10,000 motor vehicles and their relationship with GNI/p level is shown in figure 11 for the eight income categories of countries in 2000. As shown in figure 12 their mortality from road risks first increase sharply and successively decay slowly with increased GNI/p-levels respectively below and above a GNI/p of US\$ 5,000 . However, not only a GNI/p increase, but also an additional time-dependent reduction of 
the traffic-mortality relationship with GNI/p are assumed for their adjusted model prognoses. If this holds, then it follows that the predicted mortality for countries with increased GNI/p levels above 4,000 US\$ will also decrease markedly with respect to 2000. A decay of risks per motor vehicle over time also holds for country categories that have successively lower GNI/p levels, despite their increased road mortality and injury rates per amount of inhabitants. This trend difference between the fatality risk (per motor vehicle) and mortality (per inhabitant) is understood by realizing that the motorization levels of middle and low income countries grow (according to figure 10) proportionally much faster than their populations. From 2000 to 2030 the world population growth is about $38 \%$ in the UN prognosis, while the world totals of motor vehicles will become doubled in our GNI/p growth-dependent prognosis of motor vehicle fleet growth.

The fatality rate in figure 11 (not corrected for under-reporting) for the lowest income countries is 27.7 times higher than the highest income countries in 2000 , while in the timeand GNI/p-dependent model prognosis for 2030 this is increased to about 43.2 times. It illustrates the proportionally larger reductions of risks per motor vehicle in high income countries compared to low income countries. In view of the dramatic health consequences of road traffic growth in the low- and middle-income countries, one has to ask whether it is possible to achieve an additional road risk reduction by application of available knowledge to less motorized countries, whereby the latter countries learn to reduce their traffic risk faster than otherwise predicted. The learning of road crash prevention should result in low income countries having a similar, instead of a smaller risk reduction per year than high income countries. The professional knowledge for the application of effective road safety measures exists to a large extent but is not widely known in middle and low income countries. How this knowledge base can be improved, which road safety measures have a positive cost-benefit ratio, and what further is needed for road safety improvements in lower middle and low income countries, is discussed elsewhere (Koornstra, 2002b).

Although the circumstances in the low and lower-middle income countries are different from high income countries, there is no doubt that by sharing of professional road safety knowledge between high and middle or low income countries there can be considerable reduction in road traffic risks. Since effective road safety measures have not been applied adequately in lower income countries, it is likely that a progressively increasing risk reduction from the high to the low income country categories can be achieved. As discussed by Koornstra $(2002 \mathrm{a}, \mathrm{b})$ there are no reasons other than lack of professional road safety knowledge and local research in middle and low income countries, that risk reduction has not been achieved. Nearly all effective road safety measures also have a positive macro-economic return on investment, also in middle and low income countries, wherein long-term road safety investments of $0.025 \%$ of their gross national income (gross domestic product) per year are sufficient to achieve the needed risk reductions for their sustainable-safe motorization.

If the global road safety target would be that fatality risks in the lower-middle and low income countries decrease in the long run by about the same or higher pace as in the high income countries, then the relationship of GNI/p with fatality risk must be progressively reduced from the expected risk of the country category with the highest GNI/p to just over two-third of the otherwise expected risk in 2025 of the country category with the lowest $\mathrm{GNI} / \mathrm{p}$. It must be feasible to achieve from 2007 to 2025 a progressively reduced relationship between fatality rate and $\mathrm{GNI} / \mathrm{p}$ from no additional risk reduction in the highest income countries to $35 \%$ additional risk reduction in the lowest income countries with respect to the otherwise expected risks of the time- and GNI/p-dependent models. Such annually additional increases of the fatality risk reductions can only be gradually achieved over the years to 
2025 and may then be assumed to continue thereafter in the same pace. The realization of this additional prevention-learning scenario will then be sufficient to establish the goal of a worldwide sustainable-safe road traffic development in the future. From the discussed road safety research we know that the road risks in developed countries can be reduced markedly by road safety measures that are hardly applied, but are proven to be effective. Since we showed that the motorizing upper-middle income countries have learned to reduce their risks faster than the earlier motorized high income countries, we might assume that such will also become possible for the successively later motorizing lower-middle and low income countries. Moreover, the present safety levels of road infrastructure, road behaviour enforcement, and motor vehicles in low and middle income countries are much lower than in high income countries. Therefore, the learning scenario can very well be combined with the prediction scenarios of the time- and GNI/p-dependent reference or alternative reference models, where the reference model seems to reflect the extrapolation of present trends better than the alternative reference model. It is then assumed that application of available road safety knowledge for the additional risk reduction may happen earlier in developing countries than otherwise predicted by the reference or alternative reference models.

\section{Scenario predictions for road deaths and serious injuries up to 2050}

In tables 6-9 the road fatalities and serious injuries in the eight income categories of countries are given for 2000 and their predictions for 2010, 2020, 2030, 2040, and 2050 in four scenarios, all based on annual growth percentages of GNI/p of the WB for 2000-2015 and the diminishing population growth percentages of the $\mathrm{UN}$ for the decades to 2050 . The first scenario assumes a decreased slope of relationship between fatality rate and GNI/p (given in figure 11), where the slope decrease depends on time and the predicted 2//3-wheel motor vehicle shares. This first scenario is called: the reference scenario.

The second scenario additionally reduces the slope of the relationship between GNI/p and fatality rate, where the fatality risk for the countries in the highest income category remains the same as in the reference scenario. But, the slope of the fatality rate reduces over time progressively. The lower the growing GNI/p level prediction for the other country category is called the learning scenario. The third scenario also assumes a decreased slope of relationship between fatality rate and GNI/p (given in figure 11), where the slope decrease depends on

Table 6. Reference and learning model predictions of deaths in thousands for 2010 to 2050.

\begin{tabular}{|c|c|c|c|c|c|c|c|c|c|c|c|}
\hline \multirow[b]{2}{*}{ Group } & \multirow[b]{2}{*}{2000} & \multicolumn{5}{|c|}{ Reference scenario } & \multicolumn{5}{|c|}{ Learning scenario } \\
\hline & & 2010 & 2020 & 2030 & 2040 & 2050 & 2010 & 2020 & 2030 & 2040 & 2050 \\
\hline 8 & 76 & 55 & 39 & 27 & 19 & 12 & 55 & 39 & 27 & 19 & 12 \\
\hline 7 & 46 & 32 & 22 & 15 & 10 & 6 & 31 & 21 & 14 & 9 & 6 \\
\hline 6 & 76 & 63 & 49 & 38 & 28 & 19 & 60 & 44 & 32 & 22 & 15 \\
\hline 5 & 133 & 118 & 96 & 75 & 55 & 37 & 112 & 83 & 60 & 42 & 28 \\
\hline 4 & 170 & 148 & 120 & 93 & 67 & 45 & 139 & 101 & 72 & 49 & 32 \\
\hline 3 & 279 & 311 & 301 & 263 & 207 & 147 & 289 & 247 & 194 & 142 & 97 \\
\hline 2 & 272 & 315 & 333 & 324 & 283 & 222 & 291 & 266 & 228 & 181 & 131 \\
\hline 1 & 148 & 181 & 215 & 249 & 262 & 245 & 166 & 167 & 167 & 153 & 126 \\
\hline Total & 1,200 & 1,222 & 1,175 & 1,082 & 929 & 734 & 1,143 & 967 & 793 & 615 & 447 \\
\hline
\end{tabular}




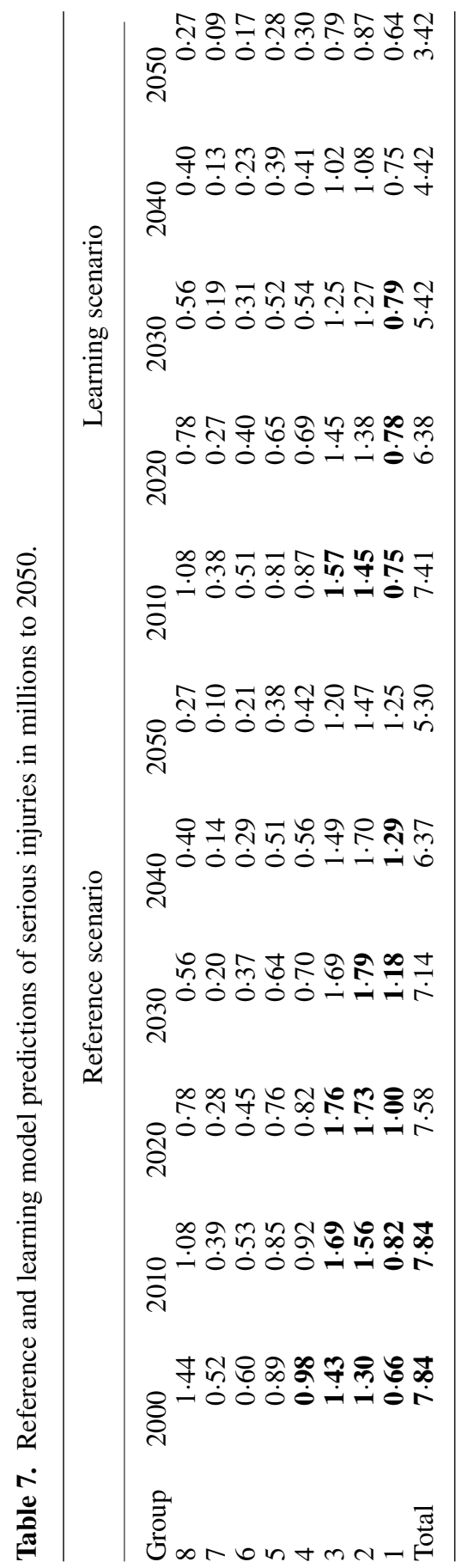


Table 8. Alternative reference and learning model predictions of deaths in thousands to 2050 .

\begin{tabular}{|c|c|c|c|c|c|c|c|c|c|c|c|}
\hline \multirow[b]{2}{*}{ Group } & \multirow[b]{2}{*}{2000} & \multicolumn{5}{|c|}{ Alternative reference scenario } & \multicolumn{5}{|c|}{ Alternative learning scenario } \\
\hline & & 2010 & 2020 & 2030 & 2040 & 2050 & 2010 & 2020 & 2030 & 2040 & 2050 \\
\hline 8 & 76 & 55 & 39 & 27 & 19 & 12 & 55 & 39 & 27 & 19 & 12 \\
\hline 7 & 46 & 34 & 24 & 16 & 11 & 7 & 33 & 23 & 15 & 10 & 6 \\
\hline 6 & 76 & 73 & 65 & 55 & 43 & 31 & 70 & 58 & 46 & 34 & 24 \\
\hline 5 & 133 & 136 & 127 & 110 & 86 & 61 & 129 & 109 & 88 & 66 & 45 \\
\hline 4 & 170 & 175 & 166 & 145 & 114 & 79 & 164 & 140 & 112 & 83 & 56 \\
\hline 3 & 279 & 368 & 424 & 436 & 391 & 303 & 342 & 347 & 322 & 269 & 119 \\
\hline 2 & 272 & 361 & 445 & 514 & 534 & 486 & 334 & 356 & 363 & 340 & 287 \\
\hline 1 & 148 & 211 & 296 & 407 & 514 & 575 & 194 & 231 & 273 & 299 & 296 \\
\hline Total & 1,200 & 1,414 & 1,587 & 1,710 & 1,710 & 1,553 & 1,322 & 1,303 & 1,246 & 1,119 & 925 \\
\hline
\end{tabular}

time and the predicted motorization level: the alternative reference scenario. The fourth scenario additionally changes the alternative reference scenario to a learning scenario, where also the fatality risk for the countries in the highest income category remains the same as in the alternative reference scenario but, the slope of the fatality rate again reduces more over growing GNI/p level prediction for the other country categories is: the alternative learning scenario.

The target for future mobility is to achieve worldwide a sustainable-safe road transport system. The four scenario predictions in the tables 6-9 clearly show that the learning scenario is needed in order to achieve that target before 2020, because in the reference, alternative reference, and the alternative learning scenarios the road fatalities and serious injuries still increase after 2020 for the countries of the lowest or both lower income categories of countries. The fatality decreases in high and upper-middle income countries are compensated by larger fatality increases in lower-middle and low income countries up to 2020 in the reference and alternative learning scenario model or up to 2020 in the alternative reference scenario (bold face typed numbers in tables 6-9 are increasing with respect to numbers 10 years earlier).

The annual risk decay percentages of the alternative reference model for the upper-middle income countries of categories 5 and 4 are markedly lower than observed in countries of these categories that have long-term time series of relevant data. As shown and discussed earlier, the countries of the upper-middle income categories 6 and 5 have or will have their fatality peaks respectively shortly before 2000 and around 2005, which is also postponed by at least 5 years in the alternative reference scenario. Therefore, it seems unlikely that the alternative reference model will be a valid scenario, but it could function as a model that describes the upper prediction levels where below the future fatalities and serious injuries will certainly be. The alternative learning, the reference, and the learning scenarios are respectively more in consistency with the discussed time series model predictions for the country categories 7,6 , and 5 (and 8 by definition). Only the learning scenario shows after 2020 worldwide a sustainable-safe development of road transport, because in that scenario the fatalities and serious injuries also decrease thereafter in countries of the lowest income category. In this scenario the world totals of fatalities and serious injuries are already reduced in 2010 due to smaller increases in the three lowest income categories of countries than reductions in the other country categories. The learning scenario may seem too optimistic, but it implicitly assumes average annual reductions of fatality rates per motor vehicle of an unchanged $4.5 \%$ in high income countries to 2050 and in lower income countries these annual rate reductions 


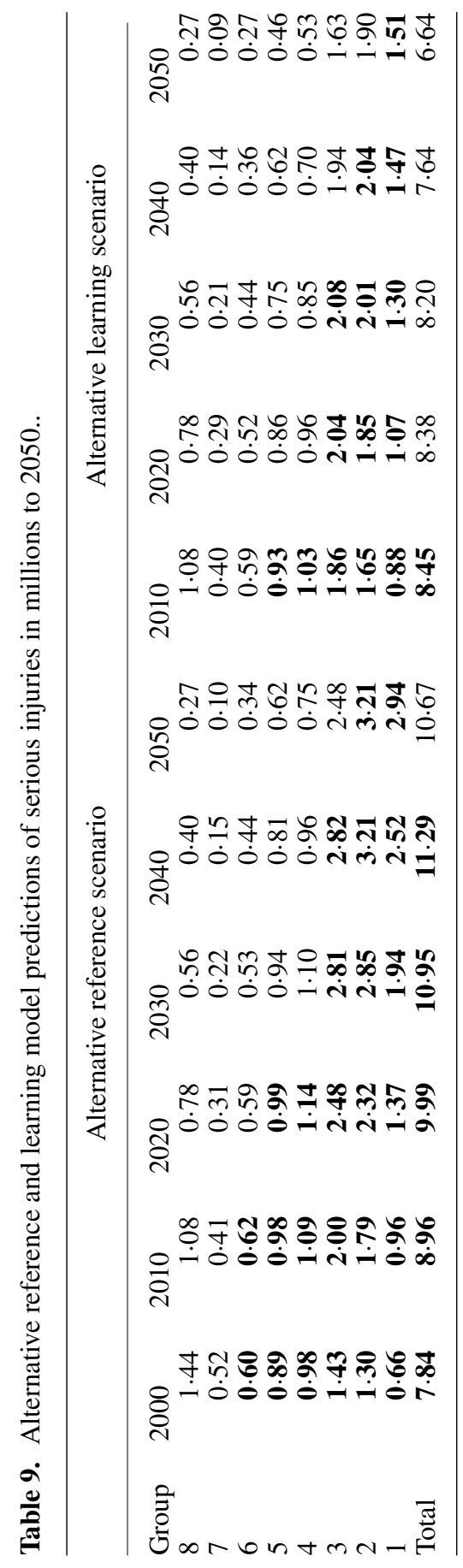


range from $2.75 \%$ to $4 \%$ around $2000-2010$ and from $4.5 \%$ to $6.5 \%$ around $2040-2050$. Since the last annual risk decay percentages are within the range of the observed values in nearly all countries that have times series of road fatality risks available over more than 25 years before 2000 (except the USA and a few low income countries with consistent time series, all countries with consistent time series show higher annual risk decay percentages than 4\%), it might be a feasible scenario.

The major obstacle for the achievement of the learning scenario is the lack of sufficient political priority for road safety (Elvik, 2003), and the general ignorance of the existence of effective road safety measures by authorities in low and middle income countries. These are the reasons why effective road safety measures are hardly implemented, despite that it would save millions of lives and seriously injured road victims, whereof several millions life-long completely or partially disabled, and also increase the welfare in developed and developing countries because the proposed road safety measures have a positive macro-economic return on investment (Koornstra 2002a,b). The political awareness of the problem is low in lowermiddle and low income countries. This is not mainly caused by the political ignorance or the wish of inhabitants, because road users themselves adapt to the existing level of road risks and thereby, accept what they experience on the road (Koornstra 1990, 2007). On the one hand there is the positive utility of motorized and non-motorized road use, but on the other hand no one likes the risk to be involved in a road accident. It is this type of ambivalence, in this case the conflict between the positive utility of road transport and the negative utility of road risks, that is psychologically solved in partial risk indifference. Moreover, differences in road traffic risks are difficult to perceive. Only road traffic situations with unusually high or low risks are consciously noticed, where extremely high risks are generally compensated by safer behaviour, but regrettably the reverse holds often for extremely safe road situations. Road accidents are not like disasters that kill and injure a mass of people in a single event, but a road injury or death occurs separately and generally concerns an unknown, distant individual. Thereby, one gets used to the average risk level in more or less the same way (but much slower) as, to the brightness level for example, in dark adaptation. Road users, therefore, are to large extent indifferent with respect to a range of risks around the average road traffic risk (Koornstra 1990, 2007). This adaptation to the average experienced risk and the ambivalent indifference for a range of risks around that average risk cause the ignorance of the road safety problem by the majority of people and the politicians, who both believe wrongly that there are very few methods to reduce the problem.

Policymakers view road accidents as random events and inevitable consequences of the benefits of motorized road transport. Nonetheless, the road safety problem is not caused by acts of gods, nor is it a matter that is out of reach for human control. It is a man-made problem that can be diminished by human action. Politicians need to be pushed to act rationally and should not be guided by psychologically understandable, but wrong reasons for the negligence of the road safety problem. They need to become better informed about the present and future extent of the road safety problem and about the urgency and potential of prevention. On the individual level road traffic risks may be ignored and regarded as far away, but collectively road traffic risks cause nowadays that over 1.2 million road users to die and that almost 7 million get seriously injured, while increases are predicted at least to 2020 if present trends continue and no effective prevention actions are taken. Preventive actions are not only the responsibility of politicians in parliament. Also, ministers and regional and local governmental authorities and their organisations as well who are professionally involved in road transport (planning, management, construction) and relevant other sectors, such as health care, legislation, police enforcement and education, have to face the growing road safety problem in a broader way and 
to take the needed prevention actions. If effective counter-measures would not exist then there would be an excuse for lack of preventive actions. However, effective road safety measures are professionally well known and also measures that have low costs and are appropriate for lower-middle and low income countries.

\section{References}

Broughton J 2003 The benefits of improved car secondary safety. Accident Analysis and Prevention 35: 527-535

Elvik R 2003 How would setting policy priorities according to cost-benefit analysis affect the provision of road safety? Accident Analysis and Prevention 35: 557-570

CEC 2003 Information and communication technologies for safe and intelligent vehicles. COM (2003) 542 final. Commission of the European Communities, Brussels

ETSC 2003 Transport safety performance in the EU - A statistical overview. ETSC, Brussel.

ETSC 1997. Transport accident costs and the value of safety. ETSC, Brussel

IRF 2002 World road statistics 1997-2001. International Road Federation, Geneva

Jacobs G D, Aeron-Thomas A, Astrop A 2000 Estimating global road fatalities. TRL-report 445 Transport Research Laboratory, Crowthorne, Berkshire

Koarnstra M J 2007 Changing choices: psychological relativity theory Leiden: Leiden university press,

Koornstra M J 2002a The global estimation of the health and economic losses from road accidents, their prognosis for 2020, the prevention potential, and the health and economic prevention benefits. Unpublished research report for the WHO. Geneva

Koornstra M J 2002b The urgency and potential for prevention of road traffic deaths and injuries. Unpublished report for the WHO, Geneva

Koornstra M J 1997 Trends and forecasts in motor vehicle kilometrage, road safety, and environmental quality. Proc. 30th ISATA symp. The motor vehicle and the environment - Entering a new century (Automotive Automation Lmt., Croydon)

Koornstra M J, Bijleveld F D, Hagenzieker M P 1997 The safety effects of daytime running lights. Report R-97-36. SWOV, Leidschendam

Koornstra M J 1995 Predicting the development of traffic fatalities in Latin-American and Caribbean countries. In Proc. of OECD-conference on Road Safety in Latin-American and Caribbean countries (OECD, Paris)

Koornstra M J 1994 The dependence of belt effectiveness on delta V. Research note. SWOV. Leidschendam

Koornstra M J 1993 Future developments of motorized traffic and fatalities in Asia. In Proc. CARS A93 OECD/ARRB Conference on Asian Road Safety. (MoT of Malaysia, Kuala Lumpur)

Koornstra M J 1990 System theory and individual risk. (Benjamin T: Driving behaviour in a social context. Paradigm, Caen)

Koornstra M J, Lynam D A, Nilsson G, Noordzij P, Petterson H-E, Wegman F, Wouters P 2003 SUNflower: A comparative study of the development of road safety in Sweden, the United Kingdom, and the Netherlands. TRL-VTI-SWOV report. SWOV, Leidschendam

Kopits E, Cropper M 2005 Traffic fatalities and economic growth. Acc. An. \& Prev. 37: 169-178

Krug E 1999 Injury. A leading cause of the global burden of disease. (WHO, Geneva)

Murray P A, Pitcher M, Galasko C S B 1993 The costs of long term disability from road traffic TRLreport accidents. TRL-report PR-45. Transport Research Laboratory. Crowthorne, Berkshire

Murray C, Lopez A 1996 The global burden of disease. (Vol. 1. Harvard Univ. Press, Cambridge, MA)

OECD-IRTAD 1994 Under-reporting of road traffic accidents recorded by the police at the international level. Special report, OECD-RTR programme. OECD, Paris

OECD-IRTAD 2002 On line data of OECD-RTR. Hosted by BASt, Bergisch Gladbach, Germany

Oei H L, Polak P H 2002 Intelligent speed adaptation (ISA) and road safety. IATSS Research 26: 45-51

Oppe S, Koornstra M J 1990 A mathematical theory for related long term developments of road traffic and safety. (Koshi, M: Transportation and traffic theory. Elsevier, New York) 
Taylor M C, Lynam D A, Baruya A 2000 The effects of drivers' speed on the frequency of road accidents. Report 421, Transport Research Laboratory. Crowthorne, Berkshire

Taylor M C, Baruya A, Kennedy J V 2002 The relationship between speed and accidents on rural single-carriageway roads. Report 511, Transport Research Laboratory. Crowthorne, Berkshire

UN 2002 United Nations population data base. Website: <www.un.org/popin>

Várhelyi A 2002 Dynamic speed adaptation in adverse conditions - A system proposal. IATSS Res. 26: 52-59

Warren D L 1982 Speed zoning and control. Chapter 17 in: Synthesis of safety research related to traffic control and roadway elements. Federal Highway Administration. Washington DC

WB 2003. World Bank Websites: <www.worldbank.org/data> and <www.worldbank.org/prospects> 